\title{
Efficacy of cognitive-behavioral therapy for adherence, depression and negative illness representations in rheumatoid arthritis patients: A randomized controlled trial
}

\author{
MR. Seirafi ${ }^{1}, \underline{\text { S. Namjoo }}^{1}$, M. Sabet ${ }^{2}$
}

\footnotetext{
${ }^{1}$ Department of Health Psychology, Islamic Azad University, Alborz, Iran

${ }^{2}$ Department of Psychometrics and Quantitative Psychology, Department of Psychology, Islamic Azad University, Roudehen, Iran
}

Corresponding Address: Sara Namjoo, Moazzen Blvd., Rajaee Shahr Ave., Islamic Azad University, Alborz Province, Karaj

Tel: +98-26-34182657; Email: namjoopsy@gmail.com

Received: 26 Dec 2017; Accepted: 30 Apr 2018

\section{* Abstract}

Background: Rheumatoid arthritis (RA) is a chronic inflammatory polyarthritis with multiple clinical symptoms and psychological problems, such as depression. Psychotherapy can play an important role in achieving therapeutic goals.

Objective: The purpose of this study was to determine the effect of cognitive behavioral therapy for adherence, depression (CBT-AD) and negative illness representations in people with RA.

Methods: A clinical trial was conducted in Rheumatology's clinic in a Shariaty hospital in Tehran during 2016-2017, Iran. Then, among 151 patients with rheumatoid arthritis, 28 patient were selected using the sampling judgment and half of them were randomly assigned to the CBT-AD (14 patients) and the others were in the control group (14 patients).

Psychological questionnaires including the illness perception questionnaire-revised, beck depression inventory and general adherence Scale were measured. All data were analyzed by independent ttest, Chi-square and multivariate covariance analysis.

Findings: The results showed that the baseline, post-test score between two intervention and control groups in three dimensions of illness representations $(\mathrm{P}<0.001)$, depression $(\mathrm{P}<0.001)$ and adherence $(\mathrm{P}<0.001)$ were statistically significant.

Conclusion: CBT-AD is a potentially efficacious approach for individuals with RA struggling with depression at the same time, which leads to a reduction in depression, an increase in adherence and correction of negative illness representations.

Keywords: Cognitive behavioral therapy, Rheumatoid arthritis, Illness representations, Adherence, Depression

Citation: Seirafi MR, Namjoo S, Sabet M. Efficacy of cognitive-behavioral therapy for adherence, depression and negative illness representations in rheumatoid arthritis patients: A randomized controlled trial. J Qazvin Univ Med Sci 2018; 22(2): 48-62. 


\title{
تأثير درمان شناختى رفتارى بر افسردكى، رعايت توصيههاى يزشكى و ادراكهاى منفى از إز

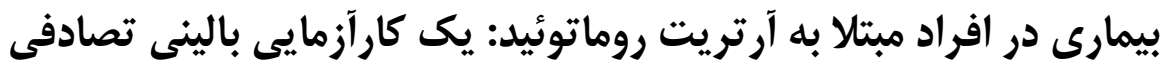

\author{
دكتر محمدرضا صيرفى '، سارا نامجو'، دكتر مهرداد ثابتج
}

أخروه روانشناسى سلامت دانشكاه آزاد اسلامى، كرج، ايران

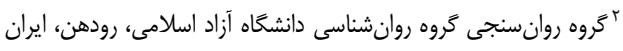

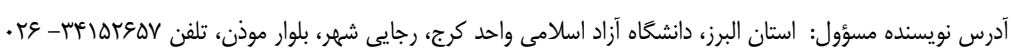
تاريخ دريافت: \$ • /

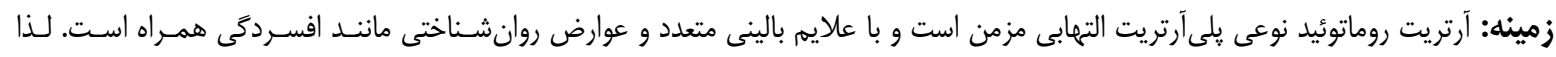

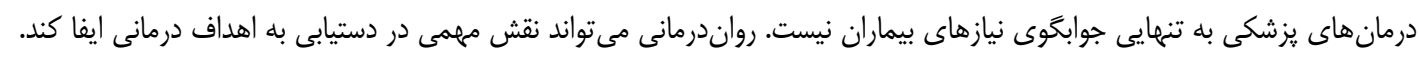

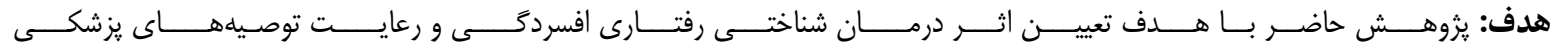
(Cognitive-behavioral therapy for adherence and depression; CBT-AD) ادراكى منفى از بيمارى در افراد مبتلا به آرتريت روماتوئيد انجام شد.

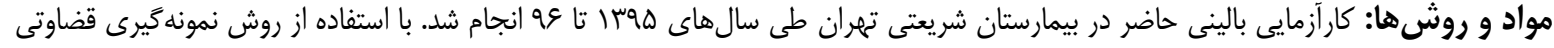

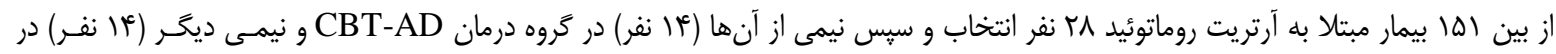

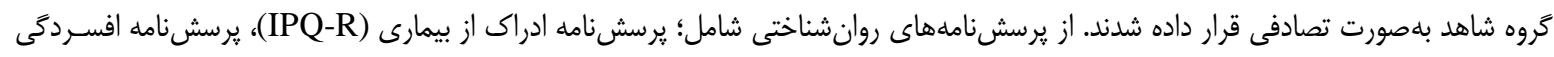

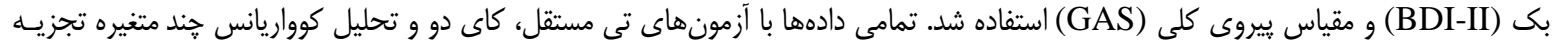
و تحليل شدند.

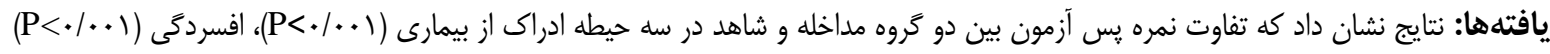

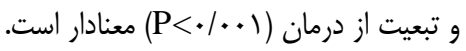

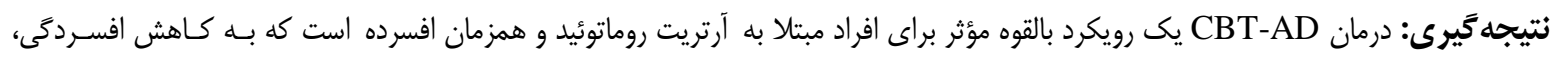
افزايش تبعيت و تعديل بازنمايىهاى ادراكى منفى منجر مى دشود. كليدوازهها: درمان شناختى رفتارى، آرتريت روماتوئيد، بازنمايىهاى ادراكى، تبعيت، افسردگى

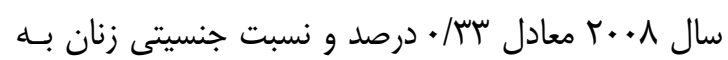

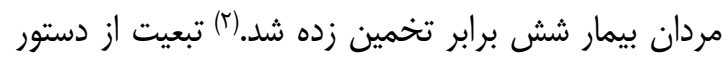

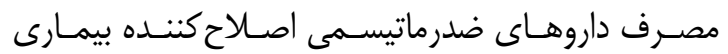
(Disease-modifying antirheumatic drugs, DMARDs)

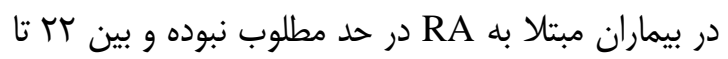

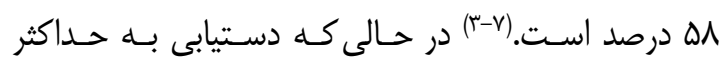

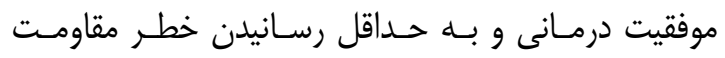

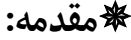

آرتريت روماتوئيـ (Rheumatoid arthritis, RA)

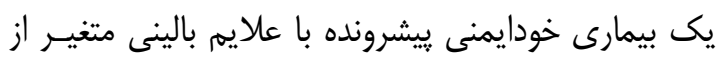

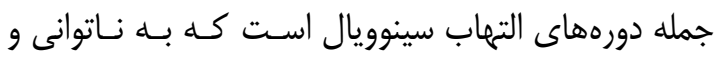
عوارض جسمى و روانشناختى در بيماران منجر مىشـودا.

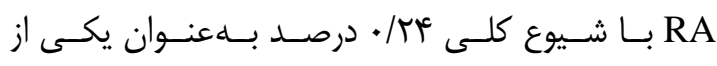

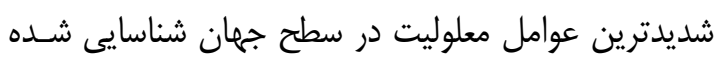
است.(') در ايران نيز شيوع نقطهاى آرتريـت روماتوئيــد در 
بلهنوان يك تهلديل، يك خارجوبى مفهومى ارايه مى كند و

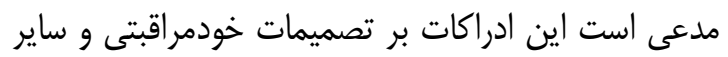

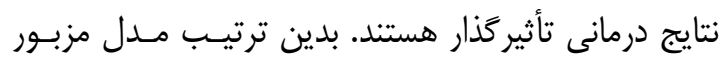

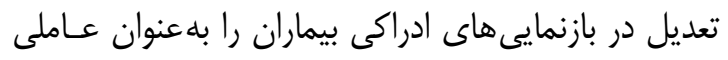

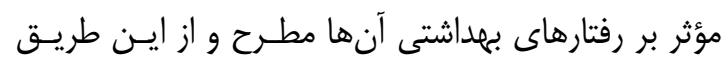

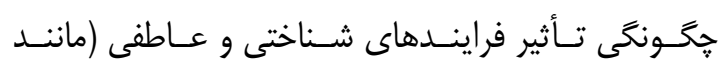

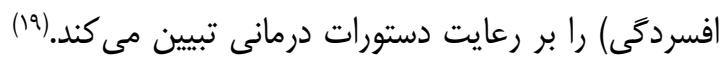

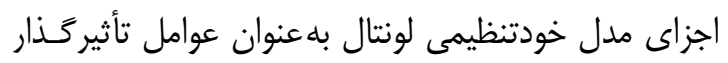

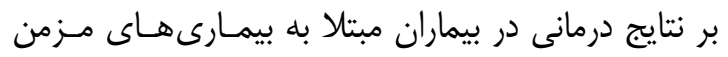

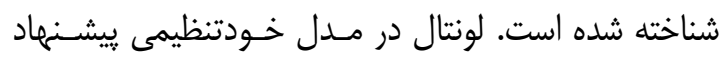

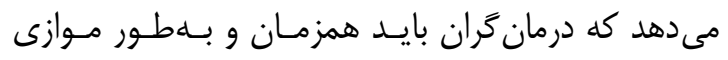

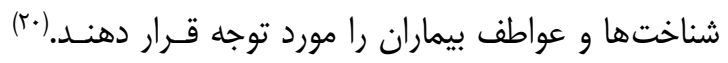

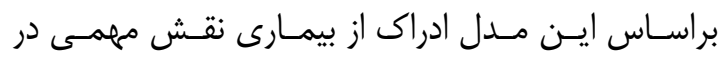

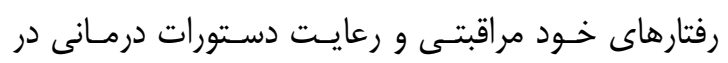
بيماران مزمن دارد.

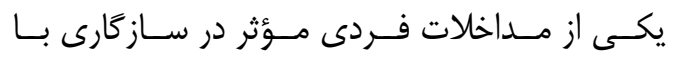

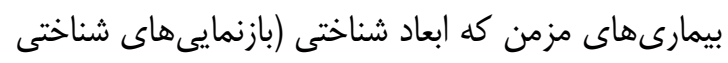

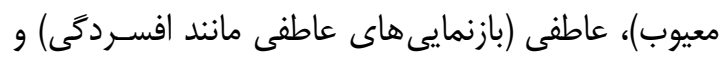

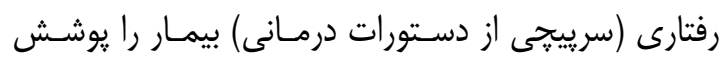

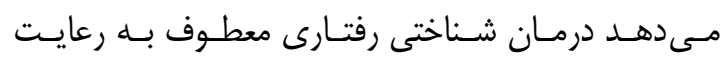

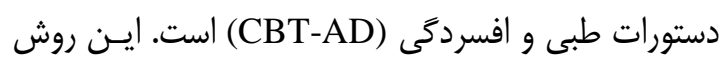

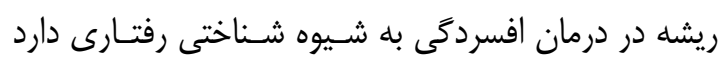

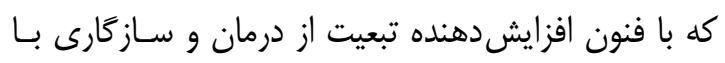

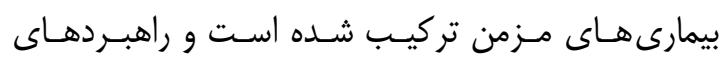

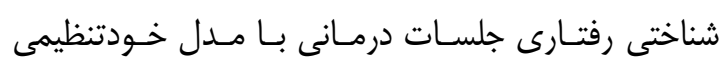

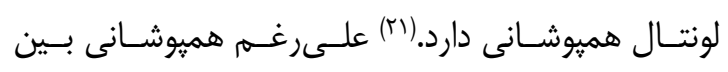

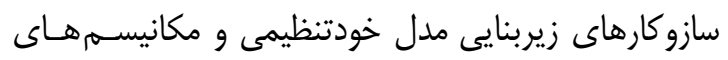

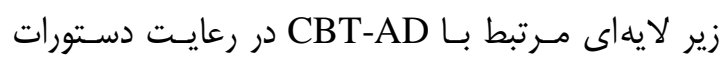

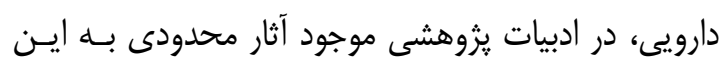

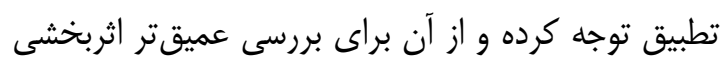

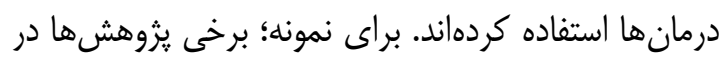

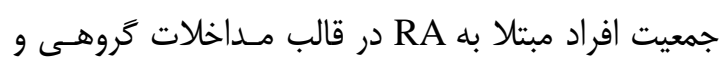

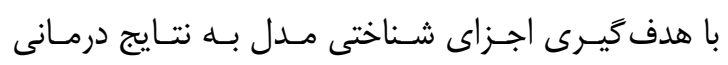

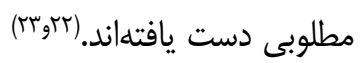

دارويى مستلزم بيش از • ج درصد رعايت دستورات درمانى

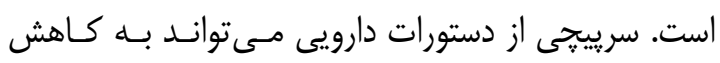

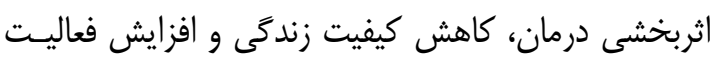

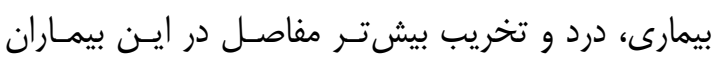

$$
\text { منجر شود.(-1-(1) }
$$

سيار بودن علايم و غير قابل ييشبينى بودن بيمارى

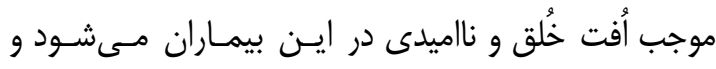

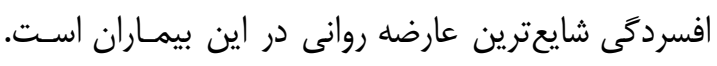

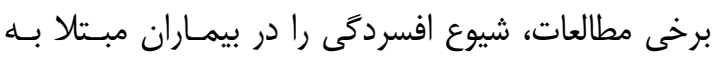

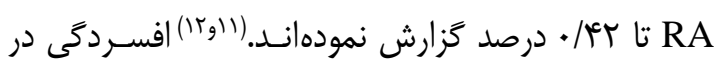

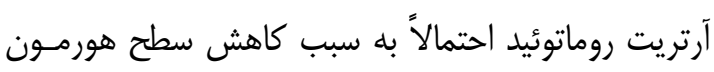

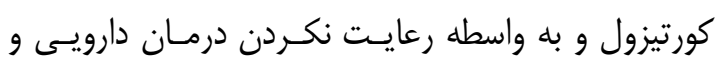
رزيمهاى يزشكى به عملكرد نامتناسبتر سيستهم ايمنى

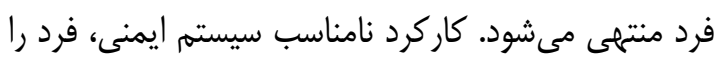

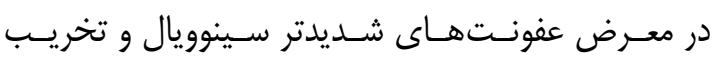

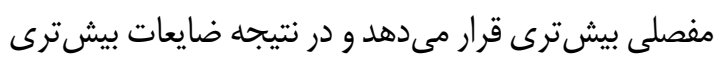

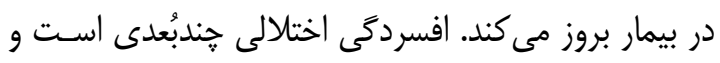

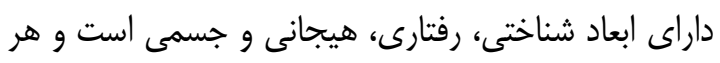

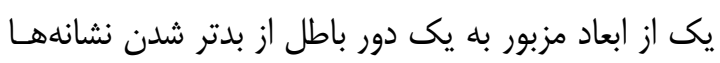

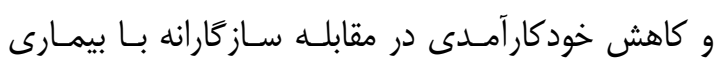

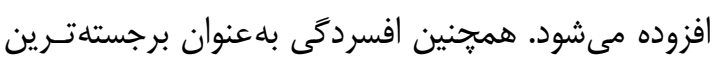

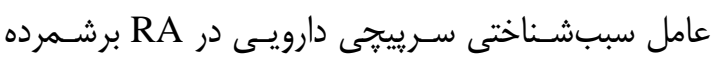

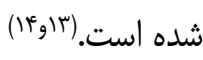

همراه شدن افسردخى و سرييجى از درمان دارويى بـانـا

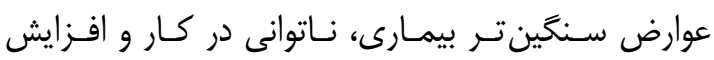

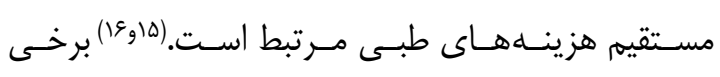

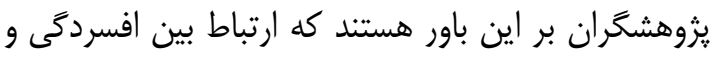

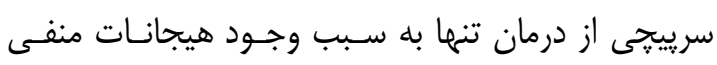

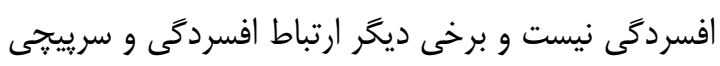

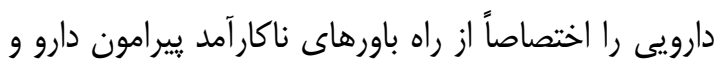

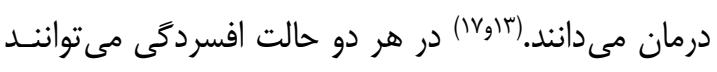

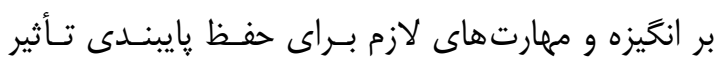

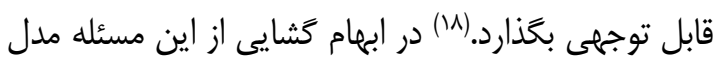
خودتنظيمى لونتال، در درى عوامل مؤثر بر ادراك بيمارى إنى 
شد(TV) و به لحاظ پاييندى به ضـوابط اخلاقى كار آزمايى بالينى مطابق با بيانيههاى اخلاقى نامبرده شركت كنندكان

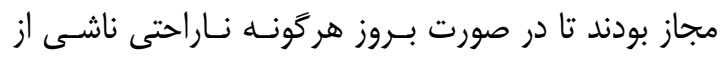

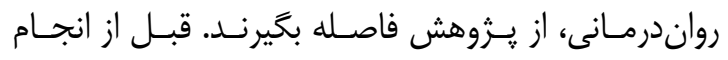

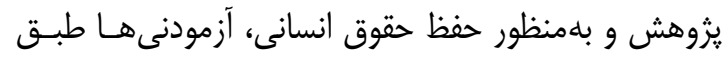

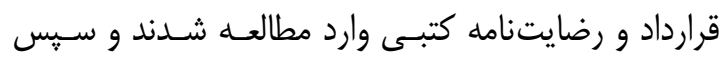

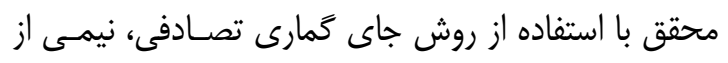

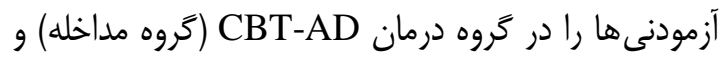

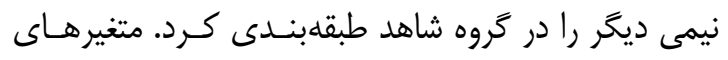

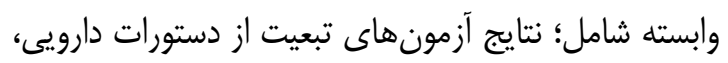

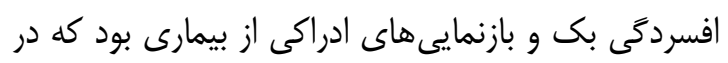
هر دو گروه در شرايطى مشابه سنجش شد بد. افراد در گروها

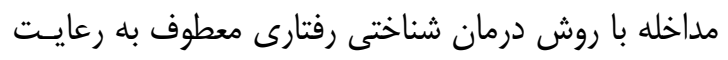

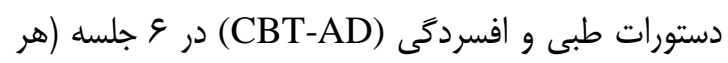

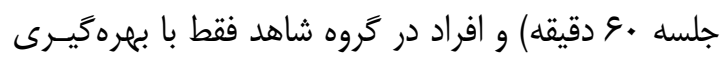

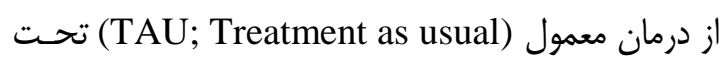

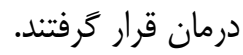

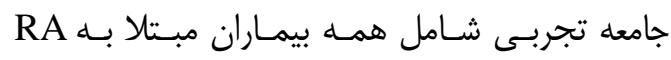

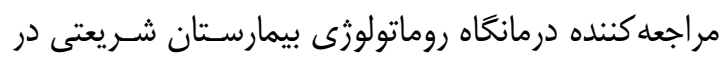

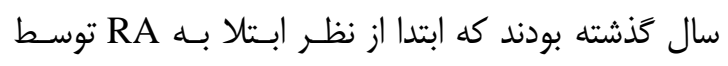

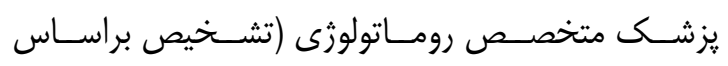

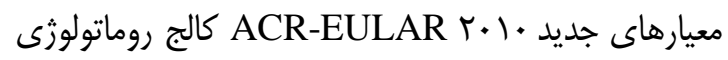

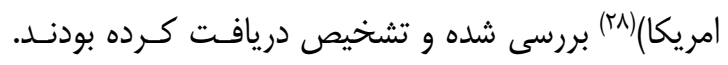

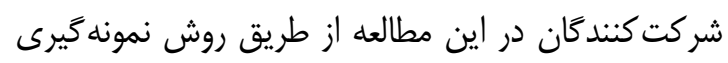

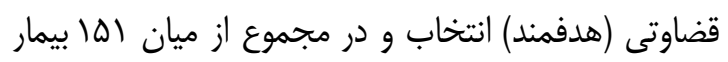

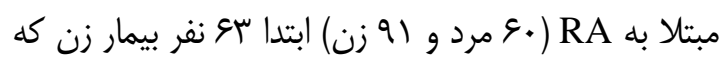
راغب به شركت در يزوهش بودند با كزارش يزشك معالج

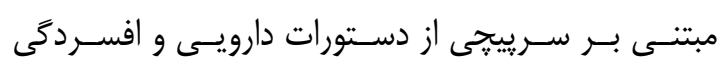

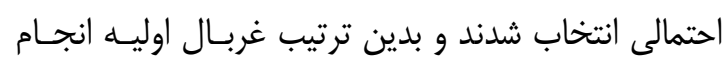
شد. سيس با كاربرد مقيـاس فعاليـت بيمـارى ( Disease معار هاء

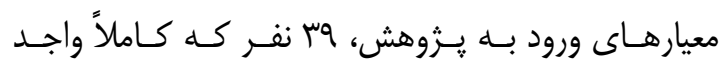
ملاكىهاى ورود به يزوهش بودند، انتخاب و از ميان آنها

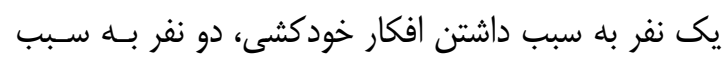

يكى از نقـاط ضـفف و محـدوديتهـاى ايـن دسـته

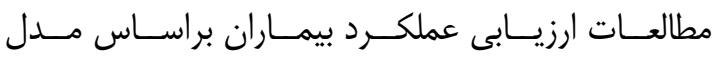

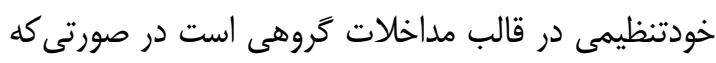
هر فردى درى خود را در رابطه بـا بيمـارى خـود دارد دارد.

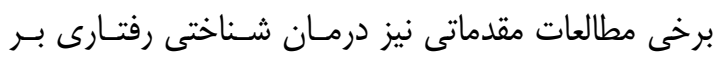

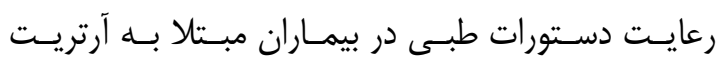

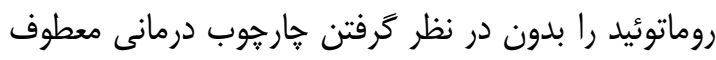

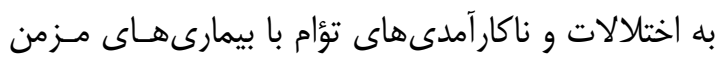

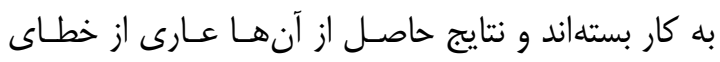

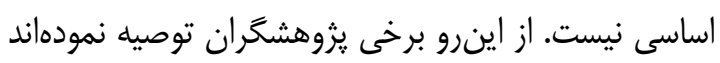

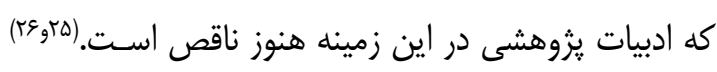

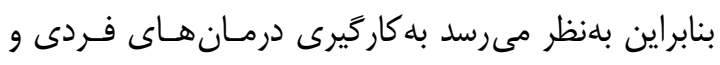

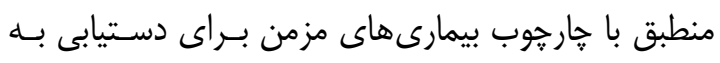

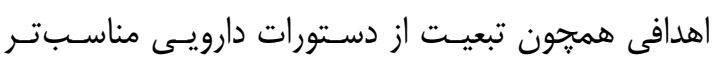

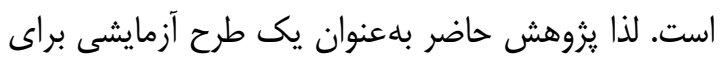

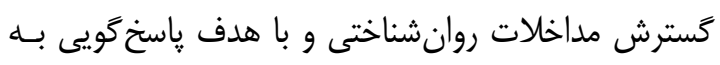
كسرى از ابهامات موجود طراحى شده است و به دو سؤات رؤال

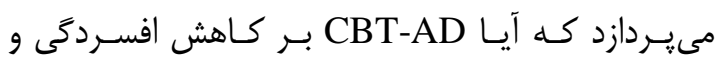

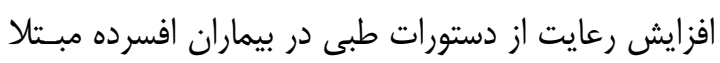

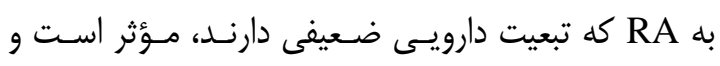

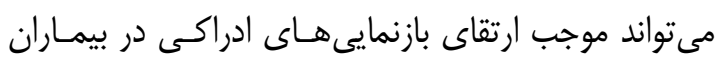

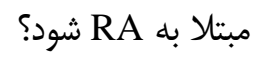

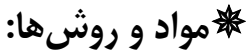

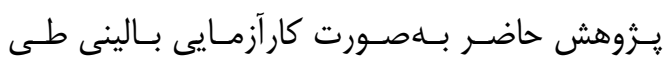

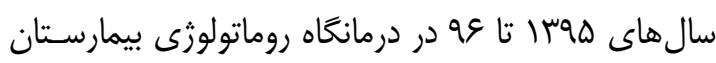

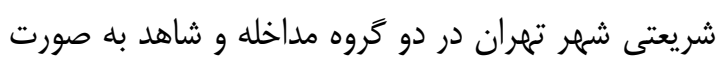

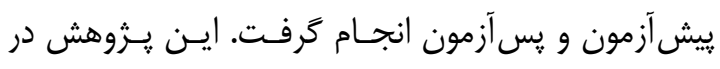

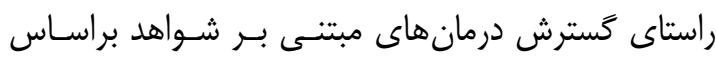

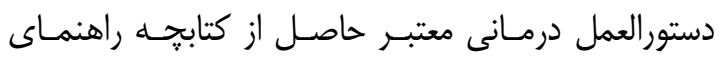

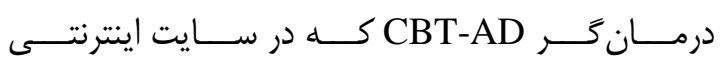
وttp://oxfordclinicalpsych.com

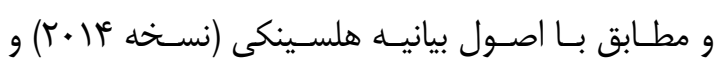
ضوابط و مقررات يزوهشهاى يز شكى بر انسانهـا انجـام 
(تشخيص از طريق كاربرد مصاحبه بـالينى سـاختار يافتـه

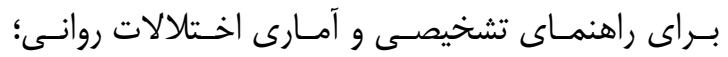
(SCIDI بك، ييروى ضعيف از توصيههاى يزشكى (براساس نمرات

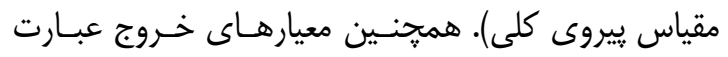

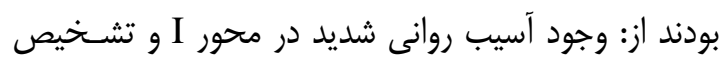

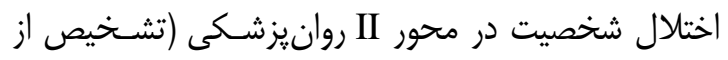
طريق كاربرد SCIDI/II در مصـاحبه تشخيصسى)، وجـود

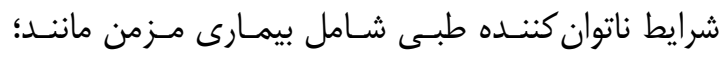

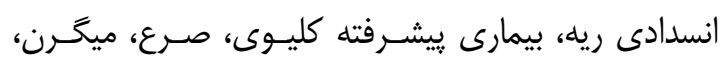

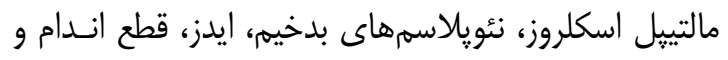
حاملنى.

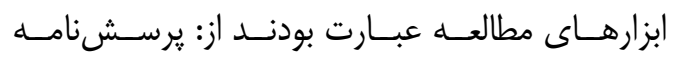

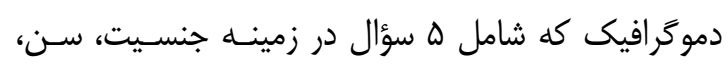

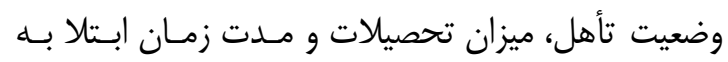
آرتريت روماتوئيد بود.

در اين يزوهش نسخه بازنخرى شده يرسش نامه ادراى بيمارى (Illness perception questionnaire-revised; IPQ-R) مورد استفاده قرار گرفت. اين يرسشنامه بلهنظور سنجش

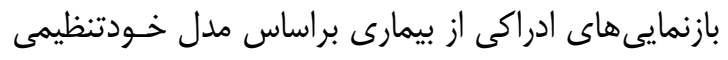

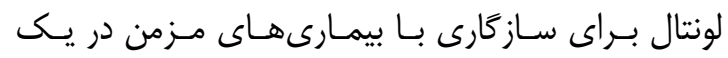

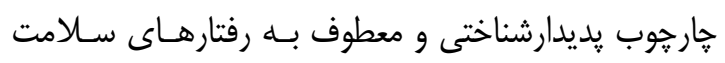

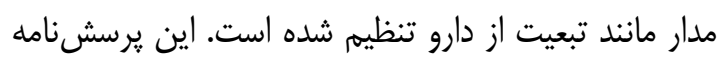

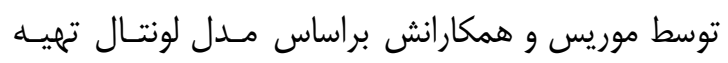

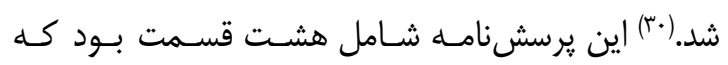

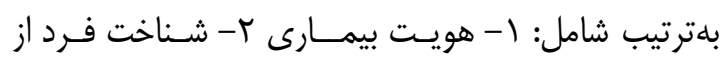

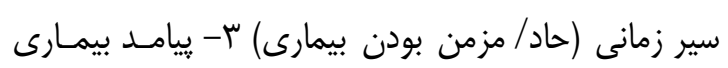

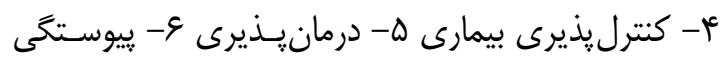

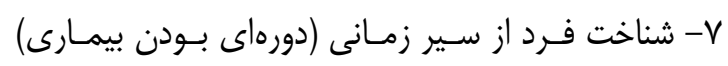

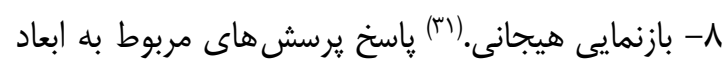

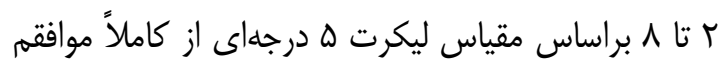

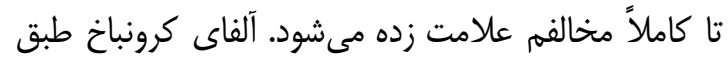

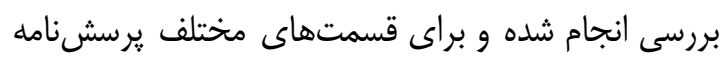

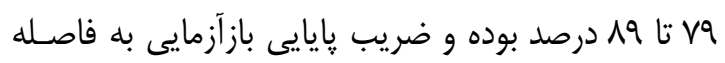

داشتن اختالالات شخصيت (محور II و سه نفر بـه سـبب داشتن اختالات طبى ديخر (يك نفر نارسايى مزمن كليه،

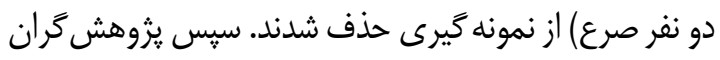

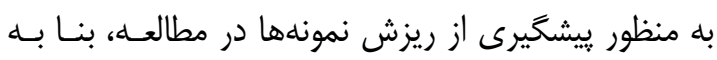

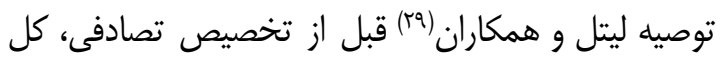

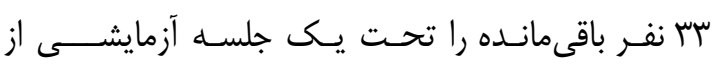
CBT-AD

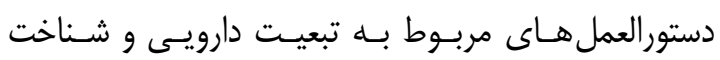

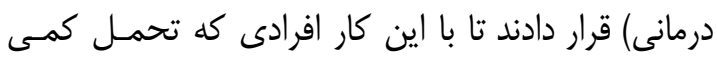

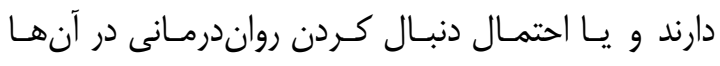

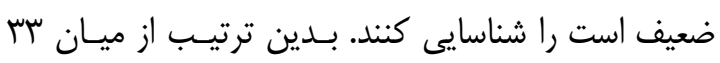

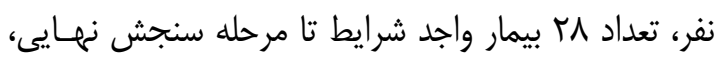

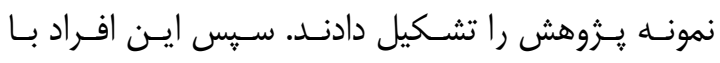

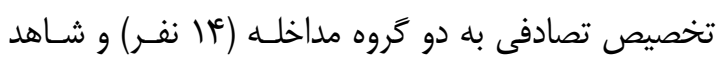
(أ)

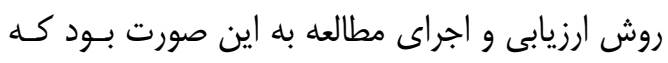

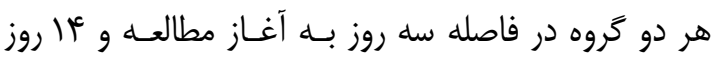

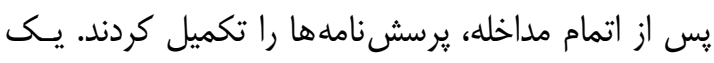

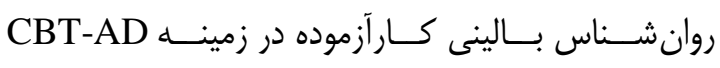
مسئوليت اجراى برنامه مداخلهاى را بر مبناى مسير تعيين

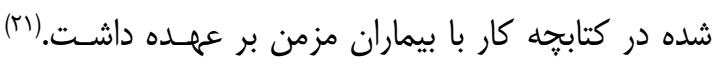

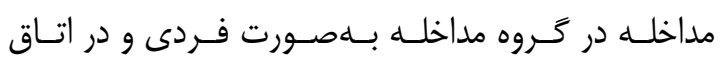

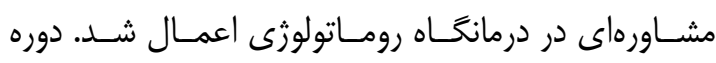

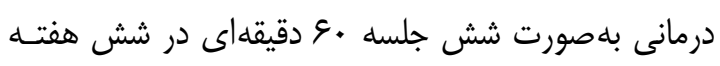

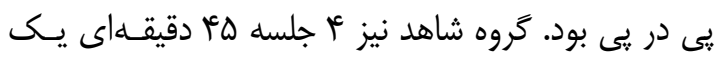

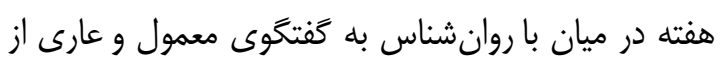
اهداف درمانى يرداختند.

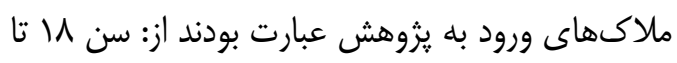

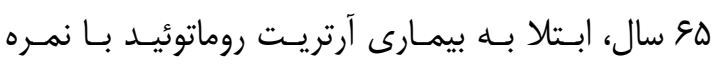

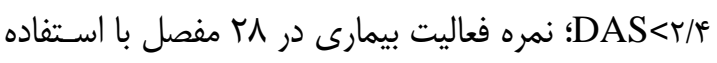

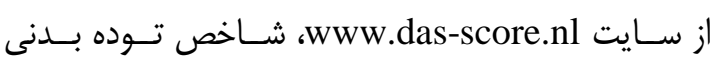
BMI<35، حـداقل تحصـيلات ديـيلم، عـدم اسـتفاده از

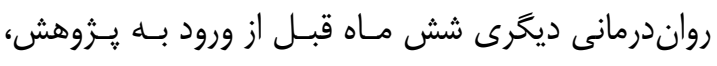

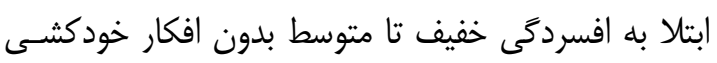


(ياسخها در محدوده (Ritchie articular index; RAI)

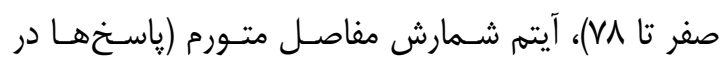

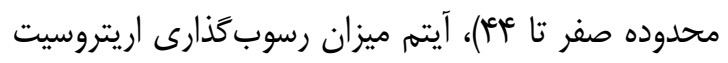
(ياسخها (Erythrocyte sedimentation rate; ESR)

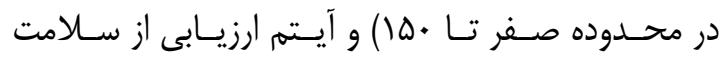

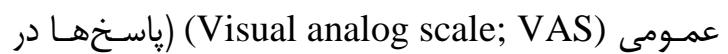
محدوده صفر تا ...1) و نمـره كلى مقيـاس در محـدوده

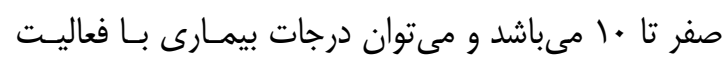

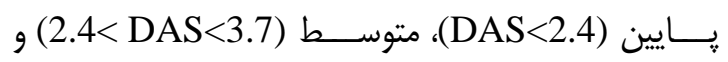

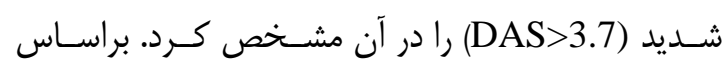

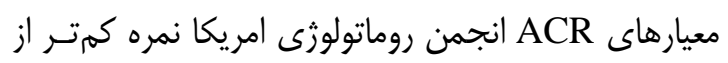

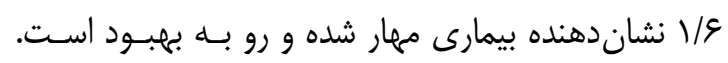

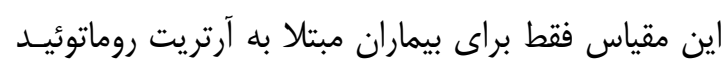

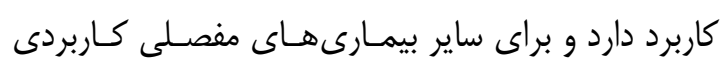

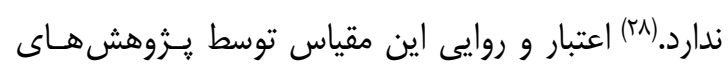

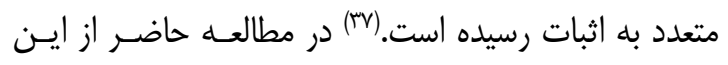

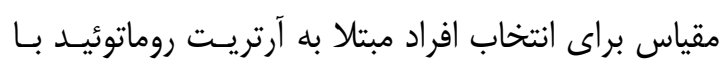
شدت بيمارى متوسط استفاده شد تا از اين طريـق متغيـر شدت بيمارى در مطالعه كنترل شود.

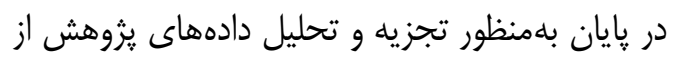
شـاخصهــــ آمـار توصـيفى و اسـتنباطى از نــرمافـزار

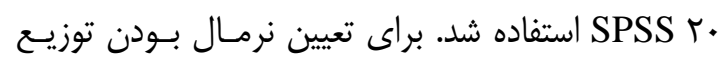

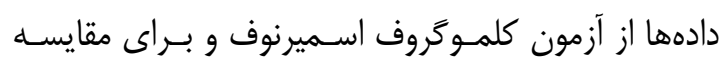

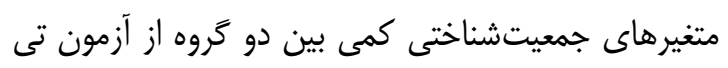

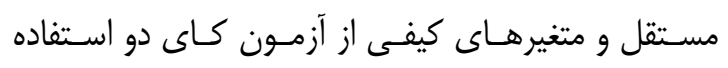

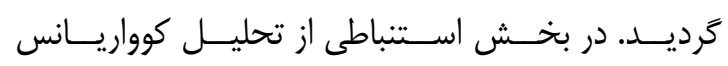

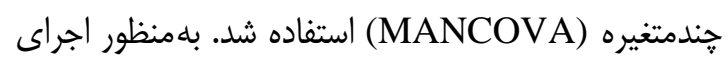

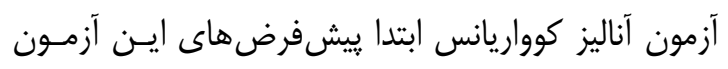

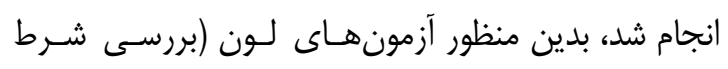

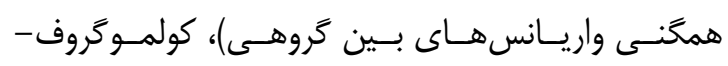
اسميرنوف (بررسى شرط طبيعى بودن توزيع نمرات) و اثـر كر كرون

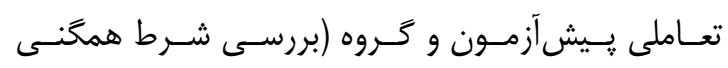

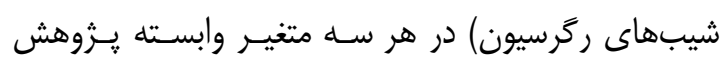

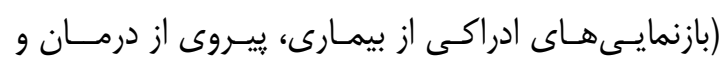

ش هف هفته براى سؤالات مختلف بـين ؤا تـا M درصـد

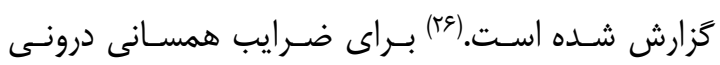

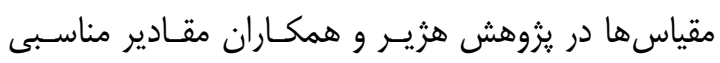
بdدست آمد.

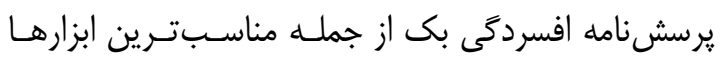

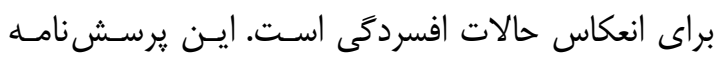

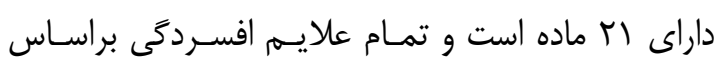

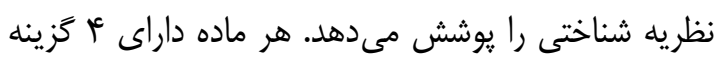

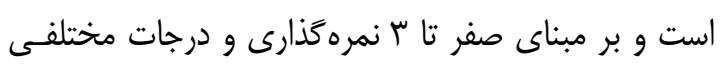
از افسردگى را از خفيف تا شديد تعيين مسى كنــد. حسداكثر

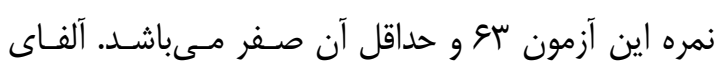

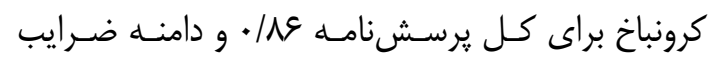

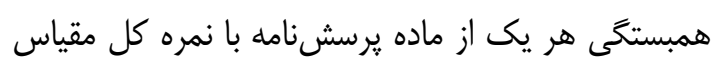

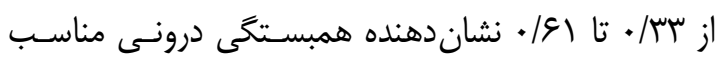

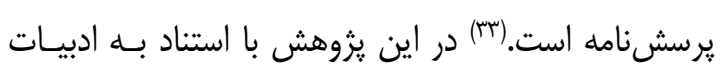

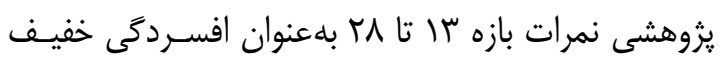
تا متوسط در نظر كرفته شده است. نَاته در مقياس بييروى كلى (GAS) در سال

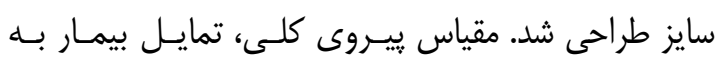

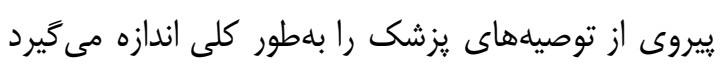

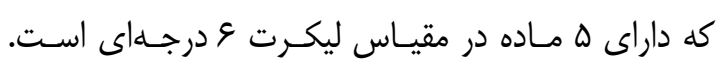

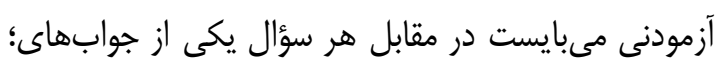

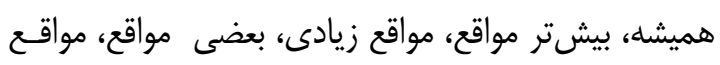

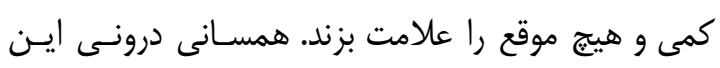

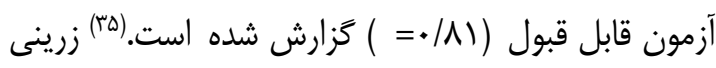

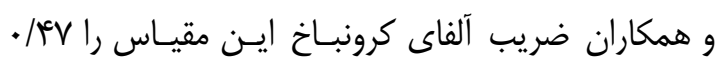

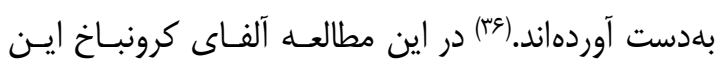
ير بشنامه وع/ • درصد بهدست آمداد. در مقياس فعاليت بيمارى، شدت بيمارى با اسـتفاده از

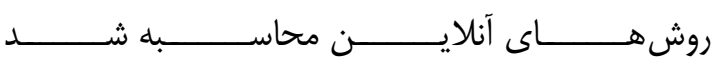
فاليــ//http:/www.das-score.nl/)

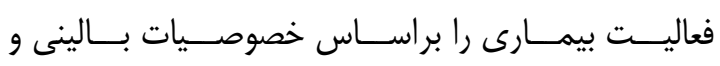

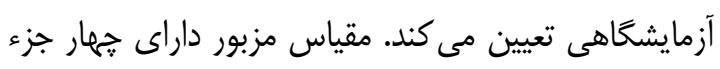

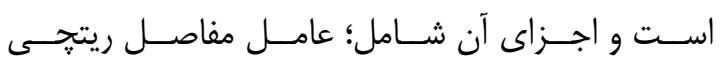


و در بين دو گروه مداخله و شاهد حداقل از لحاظ يكسى از افسردگى) انجام و ملاحظه شد.

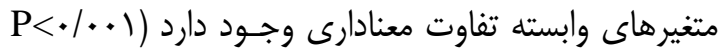

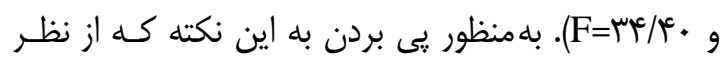

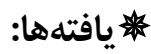

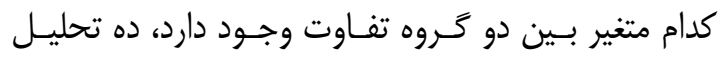
كوواريانس يك راهه در متن مانكوا ارايه شده است. نتايج آزمون كوواريانس نشـان داد كـهـ تفـاوت نمـره

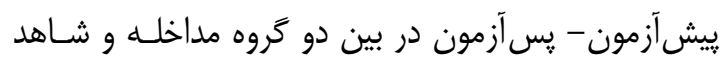

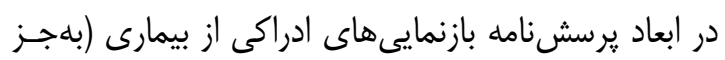

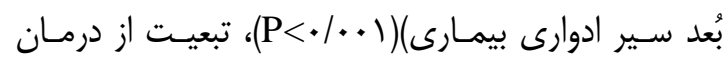

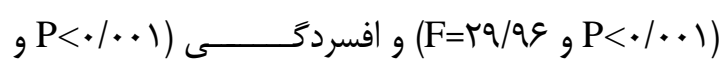
(F=|F/ معنادار است.

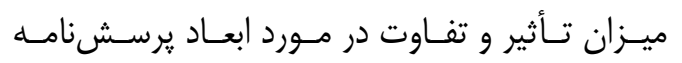

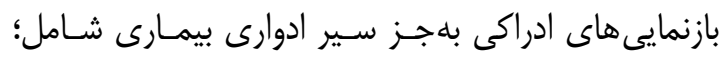

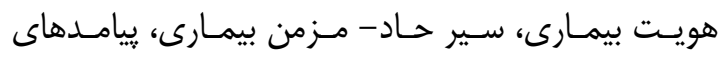

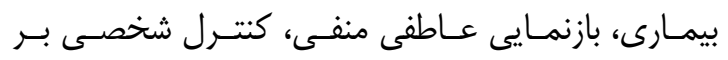

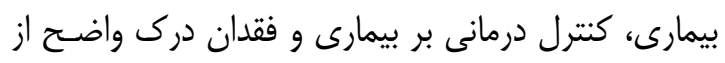

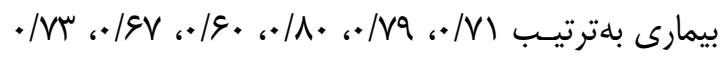

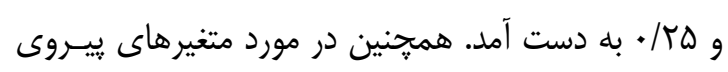

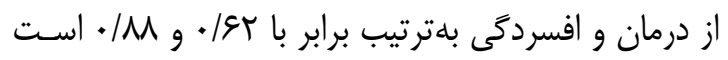

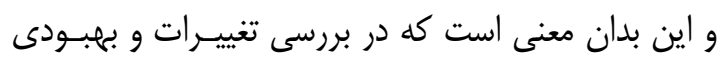

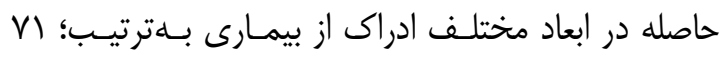

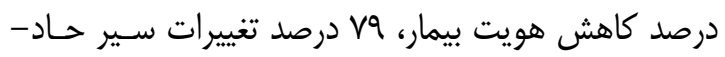

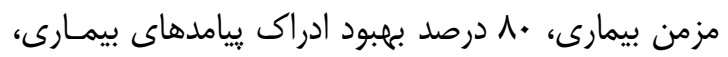

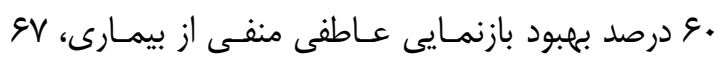

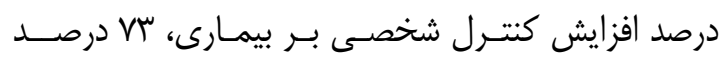

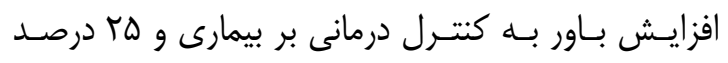

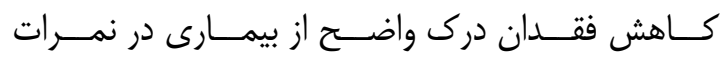

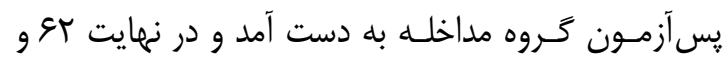

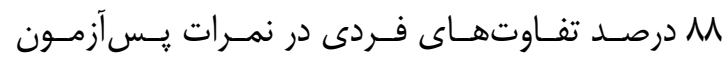

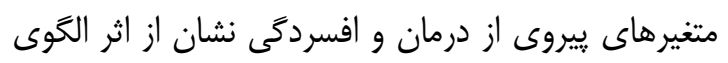
درمانى بر متغيرهاى مزبور دارد.

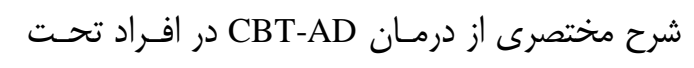

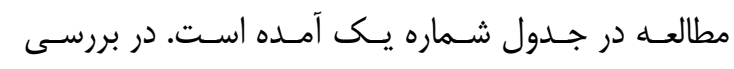

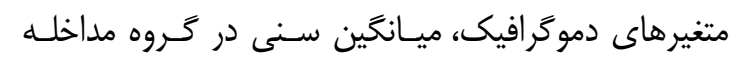

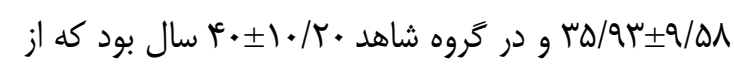

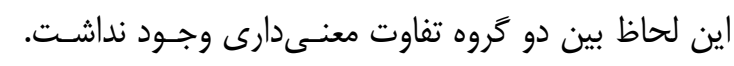

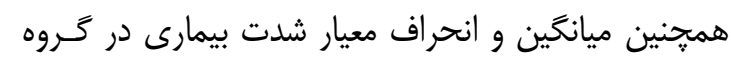

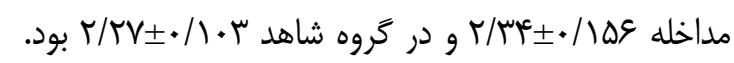

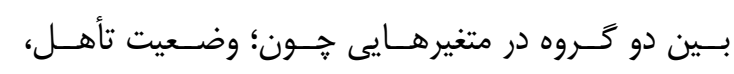
تحصيلات و شدت بيمارى تفاوت معنى دارى وجود نداشت دون

(جدول شماره r).

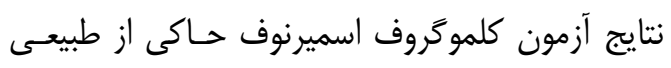

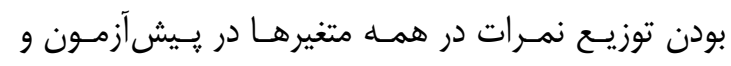
يس آزمون بود. بلهنظور توصـيف وضـعيت متغيرهـا (زيــر

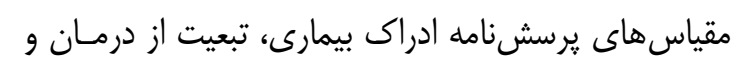

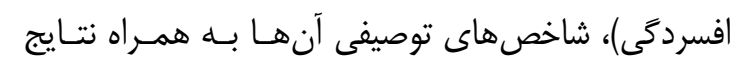

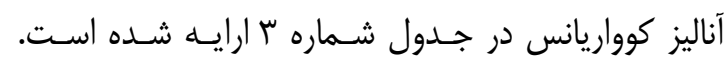

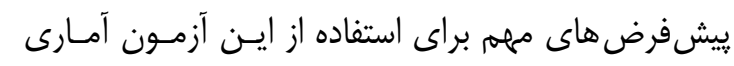
مورد بررسى قرار خرفت.

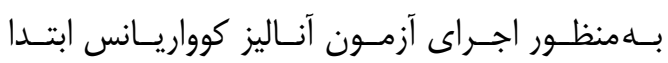

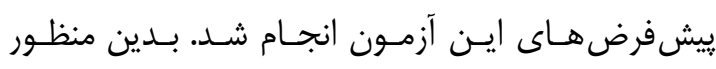

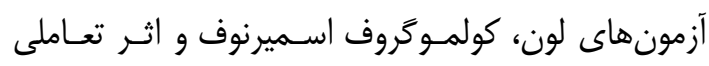

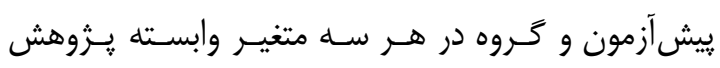

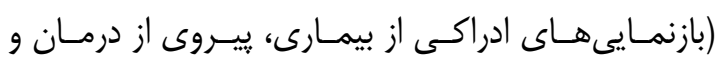

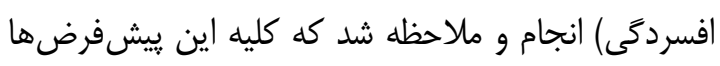

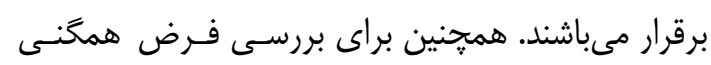

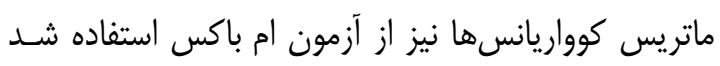

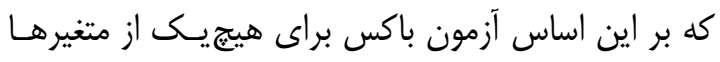

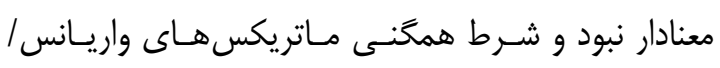

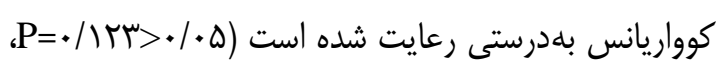

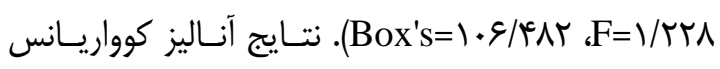

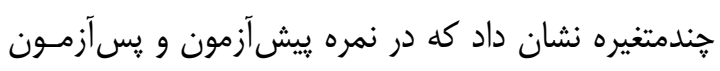




\section{جدول (- شرح مختصرى از درمان CBT-AD در افراد تحت مطالعه}

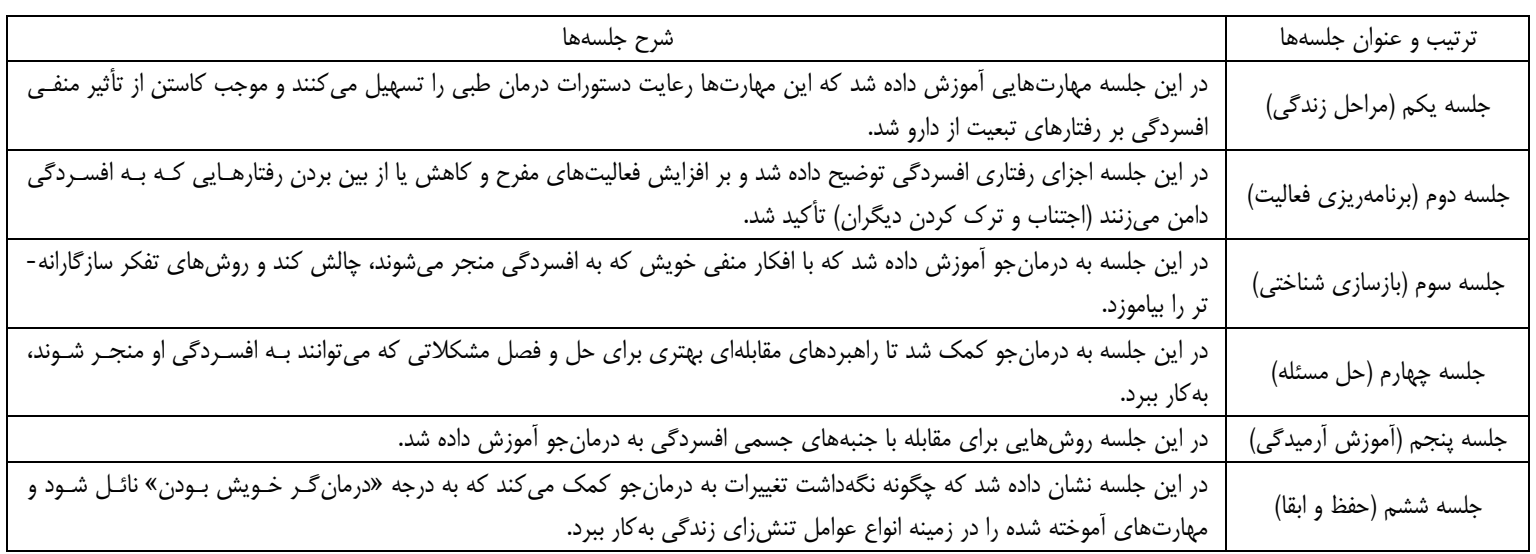

جدول r- خصوصيات دموتر افيك تروههاى مطالعه

\begin{tabular}{|c|c|c|c|c|c|c|c|}
\hline سطح معنىدارى & ضريب خى دو & درصد & كروه مداخله & درصد & كروه شاهد & & \\
\hline.$/ / 19$ & \multirow{2}{*}{ I/Ira } & $\Delta \xi / \Gamma \Delta$ & 9 & $9 \pi / D$ & 11 & ا تا r سال & \multirow{2}{*}{ مدت بيمارى } \\
\hline & & $F T / V D$ & $\Delta$ & $r V / \Delta$ & r & r تا ع سال & \\
\hline.$/ 1 Q V$ & \multirow{2}{*}{$1 / 19$} & GN/VA & 1. & $\Delta F / T \Delta$ & $\Lambda$ & دانشگاهى & \multirow{2}{*}{ تحصيلات } \\
\hline & & MI/TA & f & $\mathrm{FH} / \mathrm{VQ}$ & 4 & غيردانش اهى & \\
\hline \multirow[t]{2}{*}{.$/ \uparrow \wedge$} & \multirow{2}{*}{$\cdot / \Delta$} & $\Delta \varepsilon / T \Delta$ & 9 & TI/Ta & r & مجرد & \multirow{2}{*}{ وضعيت تأهل } \\
\hline & & $\Gamma T / V Q$ & $\Lambda$ & SN/VD & 1. & متأهل & \\
\hline
\end{tabular}

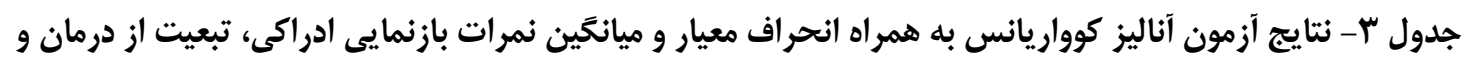

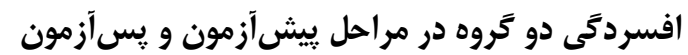

\begin{tabular}{|c|c|c|c|c|c|c|c|}
\hline \multirow{2}{*}{ سطح معنى دارى } & \multicolumn{2}{|c|}{ نتايج آزمون كوواريانس } & \multicolumn{2}{|c|}{ كروه شاهد } & \multicolumn{2}{|c|}{ كروه مداخله } & \multirow{2}{*}{ متغير } \\
\hline & ضريب اتا & $\mathrm{F}$ & يس آزمون & ي بيش آزمون & يس آزمون & ي ييش آزمون & \\
\hline$<\cdot / \cdot \cdot 1$ & $\cdot / \mathrm{VI}$ & rQ/TQ & $q / r \Delta \pm r / \Delta q$ & $Q / \Delta S \pm T / V$ & $q / \pi 1 \pm 1 / 4 q$ & 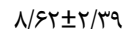 & هويت بيمار \\
\hline$<. / .+1$ &.$/ \mathrm{Vq}$ & $V \Delta / T V$ & $1 F / \backslash \Lambda \pm 1 / 8$ & $\mid r / \Lambda V \pm I / \Delta r$ & $11 / \Delta \xi \pm 1 /{ }^{\prime} \xi$ & $\mid F / .9 \pm 1 / \Delta T$ & سير بيمارى (حاد/ مزمن) \\
\hline$>\cdot / \cdot .1$ &.$/ . \mu$ & $.1 \cdot 0$ & $11 / 9 \Lambda \pm ץ / \%$ & $\mid r / \cdot . \pm F / F r$ & $\mid r / q T \pm F / N \mathcal{L}$ & $\mid r / I r \pm Y / 99$ & سير بيمارى (ادوارى) \\
\hline$<. / .+1$ &.$/ 1$ & $V E / r e$ & $I V / \Lambda \Lambda \pm r / T V$ & $\mid \varepsilon / \Delta \varepsilon \pm \mu / \cdot \Delta$ & $10 \pm T / T r$ & $|V / A V \pm \Psi / q|$ & ييامدهاى بيمارى \\
\hline$<. / \cdot+1$ &.$/ 9 \mathrm{~V}$ & rV/VT & 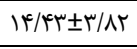 & $|r / \Lambda| \pm F / \lambda r$ & $19 \pm r / 91$ & $\mid \Delta / \Delta S \pm F / / \mu$ & كنترل شخصى بر بيمارى \\
\hline$<. / .+1$ & $\cdot / \mathrm{N}^{2}$ & $0 . / 99$ & $\mid r / r \Delta \pm \Psi / A r$ & $\mid r / K T \pm T / A r$ & $19 \pm r / 91$ & $I T / \Delta S \pm M / T K$ & كنترل درمانى بر بيمارى \\
\hline$<. / .+1$ &.$/ T \Delta$ & s/TF & $|F / g r \pm \Delta / F|$ & $\mid r / 9 \Lambda \pm \varepsilon / \cdot \varphi^{c}$ & $\mid V \pm r / 9 \Lambda$ & $\mid r / \Delta S \pm \Delta / F \varphi$ & فقدان درى واضح از بيمارى \\
\hline$<\cdot / \cdot+1$ &.$/ 8$ & $r V / . q$ & $19 / 9 \Lambda \pm V / F Y$ & $19 / 1 r \pm N / r$ & $\mid Q / \backslash \Lambda \pm F / \Lambda F$ & $r / \Delta \pm N / r r$ & بازنمايىهاى عاطفى منفى \\
\hline$<\cdot / \cdot \cdot 1$ & . 194 & rq/৭६ & $|r / \mu| \pm r / 91$ & $I r / g r \pm r / V r$ & $N / \Delta \pm Y / \Lambda V$ & $\mid f / \Lambda \Lambda \pm \mu / K r$ & ي ييروى از درمان \\
\hline$<\cdot / \cdot+1$ &.$/ \mathrm{M}$ & $|F \Psi / \lambda|$ & $r M / .9 \pm \Psi / A r$ & $r \mid / \& \Lambda \pm F / \mu r$ & $\mid r / T \Delta \pm r / \& V$ & $r T / V \Delta \pm Y / A r$ & افسردگى \\
\hline
\end{tabular}


جدول ع- نتايج تحليل كوواريانس يك راهه در متن مانكوا در متغيرهاى بازنمايىهاى ادراكى، بيروى از درمان و افسردكى

\begin{tabular}{|c|c|c|c|c|c|c|c|}
\hline ضريب اتا & سطح معنادارى & $\mathrm{F}$ & ميانگين مجذورات & درجه آزادى & مجموع مجذورات & & منبع تغييرات \\
\hline.$/ \mathrm{VI}$ & $.1 .+1$ & FA/TA & $r N / M$ & 1 & $r N / M$ & لِ & \multirow{2}{*}{ هويت بيمار } \\
\hline & & & . & $M$ & $11 / r 1$ & خطا & \\
\hline \multirow[t]{2}{*}{.$/ \mathrm{V} 9$} & $.1 .+1$ & $V \Delta / T V$ & $\mathrm{FV} / \mathrm{MA}$ & 1 & $\mathrm{FV} / \mathrm{MA}$ & يس آزمون & \multirow{2}{*}{ سير بيمارى (حاد/ مزمن) } \\
\hline & & & . & $M$ & $11 / 41$ & خطا & \\
\hline \multirow[t]{2}{*}{.$/ . r$} & $\cdot|\lambda|$ & $.1 . \Delta F$ & .1 .99 & 1 & $.1 . .9$ & ل يسآزمون & \multirow{2}{*}{ سير بيمارى (ادوارى) } \\
\hline & & &.$/ 1$ & $M$ & 1/199 & 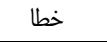 & \\
\hline \multirow[t]{2}{*}{$\cdot / \Lambda$} & $.1 .+1$ & $V E / r F$ & FIII & 1 & F & مِ & \multirow{2}{*}{ ي ييامدهاى بيمارى } \\
\hline & & &.$/ 94$ & 11 & $11 / 19$ & خطا & \\
\hline \multirow[t]{2}{*}{$.19 \mathrm{~V}$} & $.1 .+1$ & $r V / V T$ & سא/אות & 1 & سא/או11 & يس آزمون & \multirow{2}{*}{ كنترل شخصى بر بيمارى } \\
\hline & & & $r / \cdot \Lambda$ & $M$ & $\Delta Q / F \Delta$ & خطا & \\
\hline \multirow[t]{2}{*}{$\cdot / \mathrm{Nr}$} &.$/ .+1$ & $0 . / 99$ & $1 \cdot \Delta / \& \Gamma$ & 1 & $1 . \Delta / \& T^{\prime}$ & 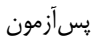 & \multirow{2}{*}{ كنترل درمانى بر بيمارى } \\
\hline & & & $r / \cdot V$ & $M$ & $r V / T \Lambda$ & 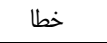 & \\
\hline \multirow[t]{2}{*}{.$/ T \Delta$} & $.1 .4 t$ & $g / T^{c}$ & 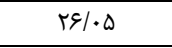 & 1 & rel.0 & 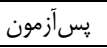 & \multirow{2}{*}{ فقدان درك واضح از بيمارى } \\
\hline & & & $r / I V$ & M & $v \Delta / \cdot \Lambda$ & خطا & \\
\hline \multirow[t]{2}{*}{.19} & $.1 .+1$ & $r V / . q$ & $r+1 . t$ & 1 & $r t \cdot 1 \cdot r$ & 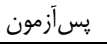 & \multirow{2}{*}{ بازنمايىهاى عاطفى منفى } \\
\hline & & & $N / I T$ & $M$ & $\mid 1 \& / 19$ & خطا خا & \\
\hline \multirow[t]{2}{*}{.$/ \mathrm{M}$} &.$/ . .1$ & $|f F / \lambda|$ & $\Delta r \cdot / g r$ & 1 & $\Delta r \cdot / g T$ & يس آزمون & \multirow{2}{*}{ افسردگى } \\
\hline & & & r/GT & $M$ & $9 D / 19$ & خطا & \\
\hline \multirow[t]{2}{*}{. } &.$/ . .1$ & rq/Q & $91 / \% 1$ & 1 & $91 / \% 1$ & يس آزمون & \multirow{2}{*}{ 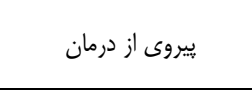 } \\
\hline & & & $r / \cdot r$ & $M$ & $\Delta F / A F$ & خطا & \\
\hline
\end{tabular}

بسته مداخلاتى به شيوه شناختى رفتارى را بر شاخصهاى

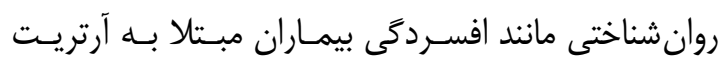

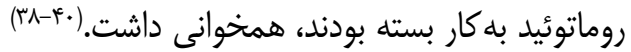

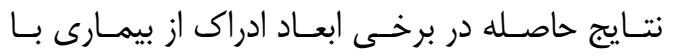

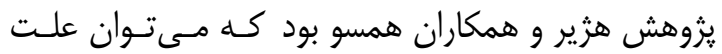

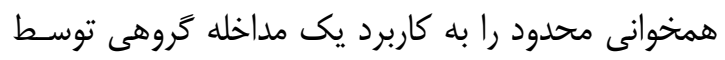
هزير و همكارانش بر مبناى مدل خودتنظيمى بر بازنمايى

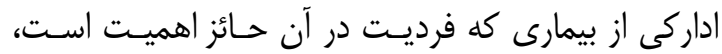

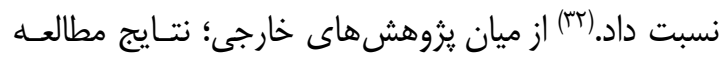

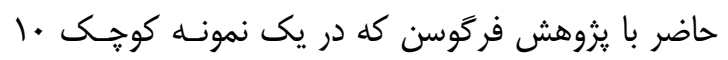
نفره اثربخشى يروتكل تركيبى از تبعيـت درمـانى، درمـان

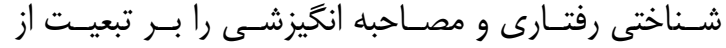

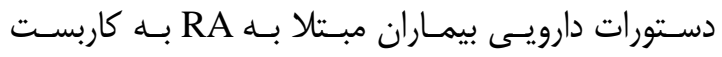

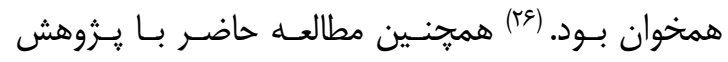

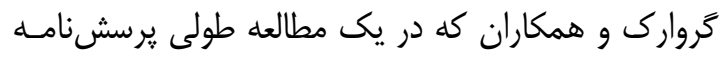

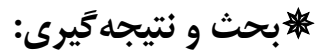

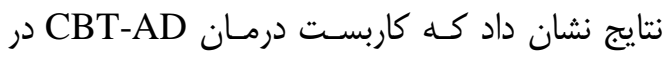

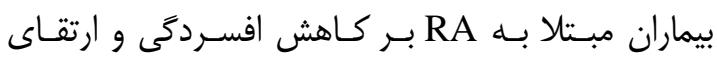

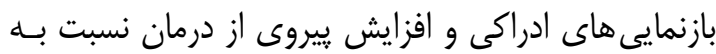

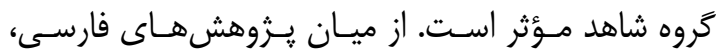

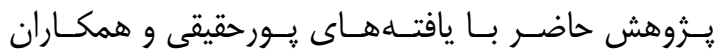

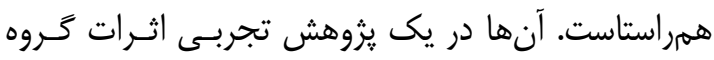
درمانى شناختى رفتارى را بر بازنمايىهاى ادراكى و برخى

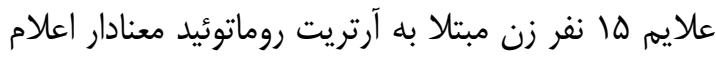

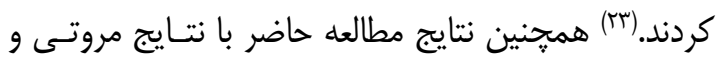

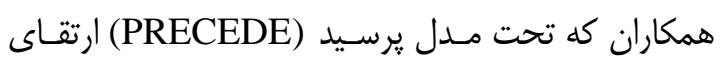
خوكارآمدى را بلعنوان راهكارى براى افزايش فعاليتهاى

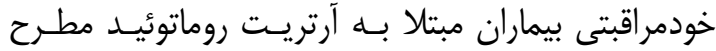

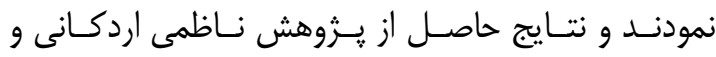

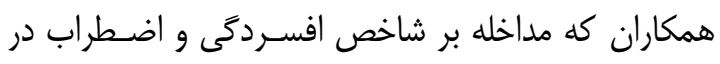

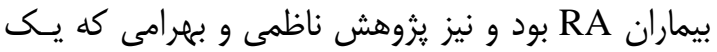


》هويت بيمار " تأكيد كلى جلسات بر اين بود كـه توانمنــــ بودن براى مديريت به هويت فرد ربطى ندارد و مـديريت

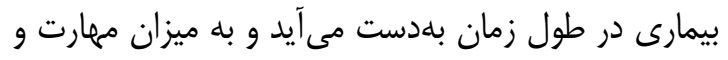

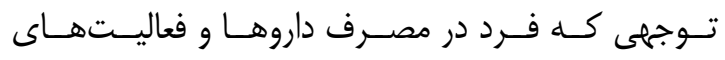
سلامتمدار از خود نشان مىدهد، مرتبط است.

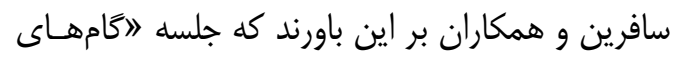

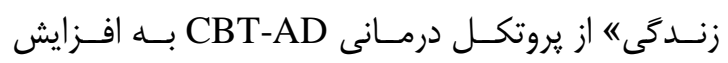

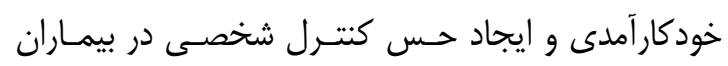

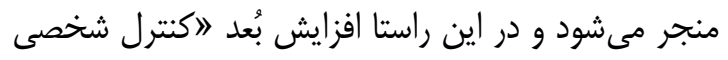

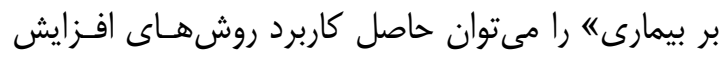

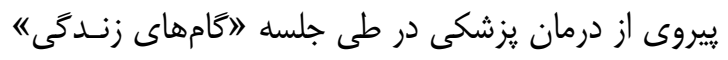

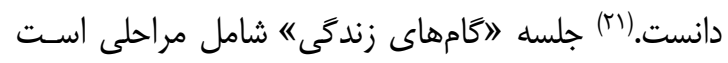

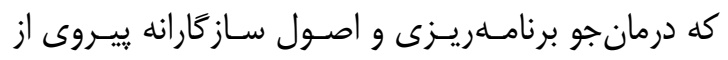

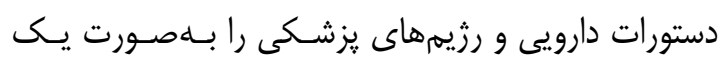

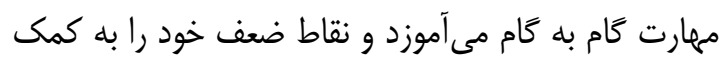

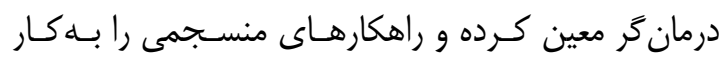

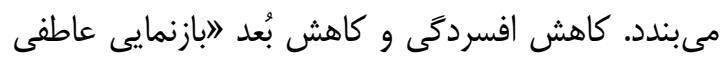
منفى" را مىتوان حاصل از جلسه برنامهريزى فعاليتهاى

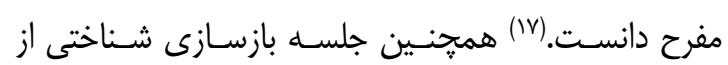
طريق شناسـايى تحريفـات شـناختى و جـايكزينى افكـار

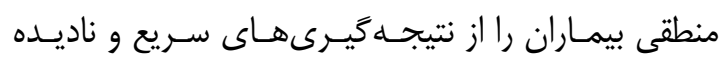

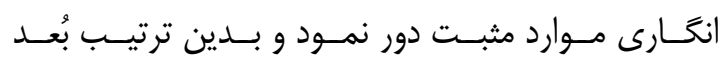

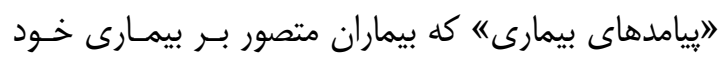
بودند، كاهش يافت. با در نظـر كـرفتن ايـن مهـهم كـهـ ابـتلا بــهـ آرتريـت

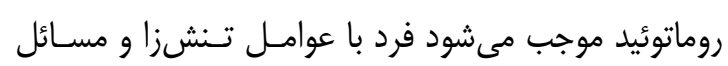

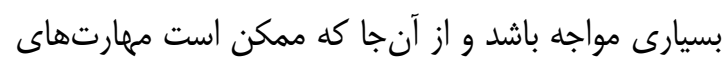

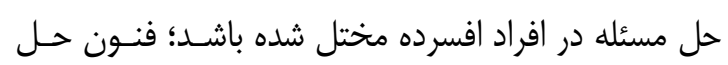

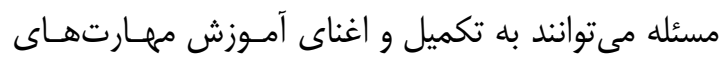

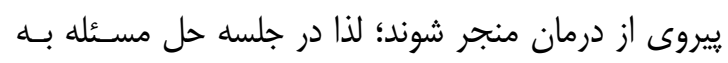

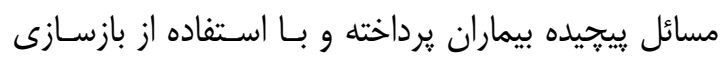

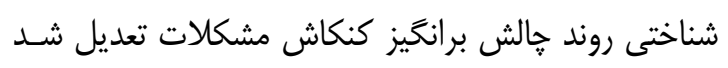

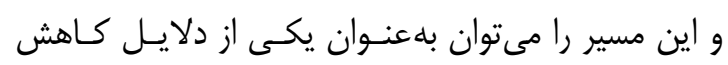
افكار ييرامون بُعد "مزمن و حاد بودن بيمارى" بهرئ برشمرد.
ادراك از بيمارى را در يِيشبينى شاخصهـاى جسـمانى و

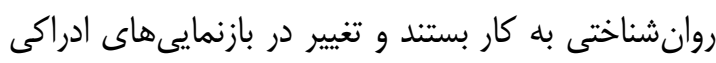

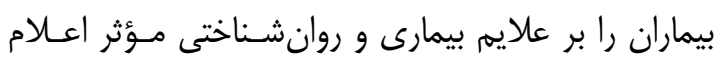

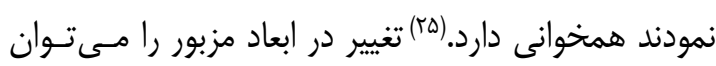

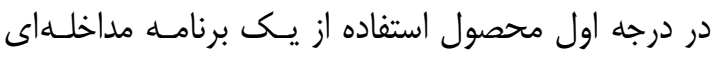

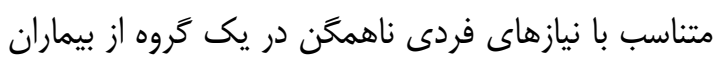

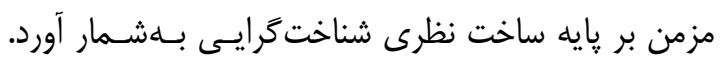
درمان CBT-AD همخوان با مدل خودتنظيمى لونتال بر باري تأثير ابعاد عاطفى و شناختى افراد بر روند كلى ردان رفتارهـاى

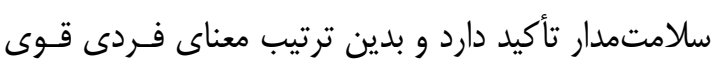

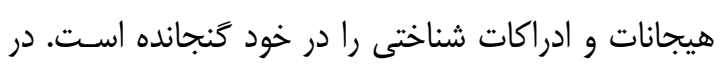

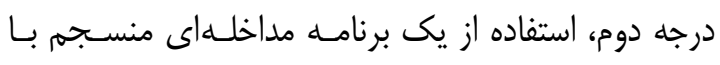

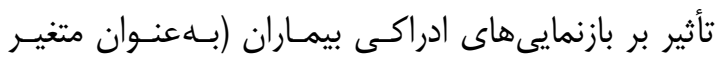

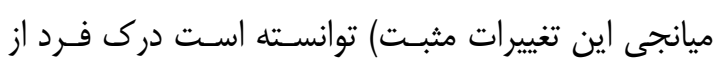

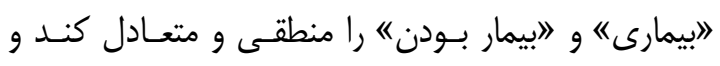
بدين ترتيب موجب كاهش افسردگى و افزايش تبعيـت از مصرف داروهاى ضدروماتيسمى شود.

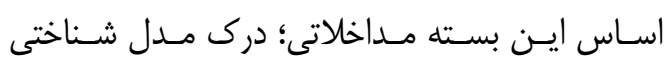

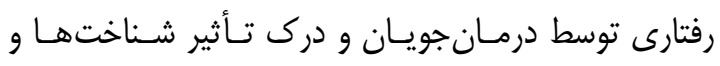

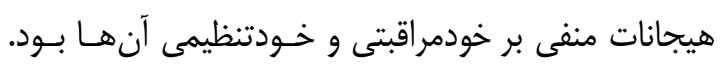

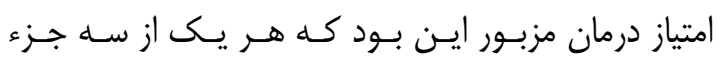

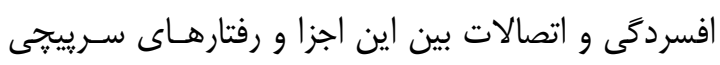

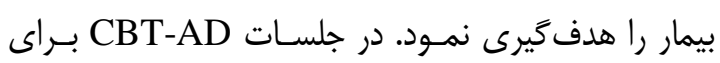

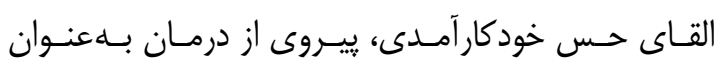

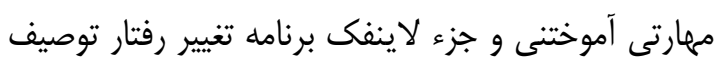

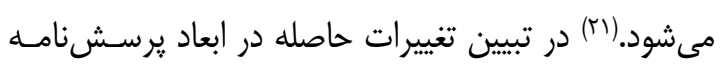

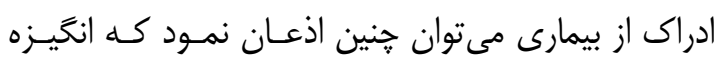

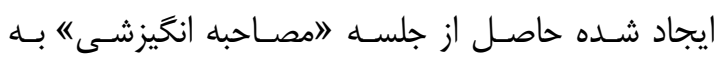

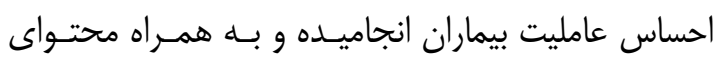

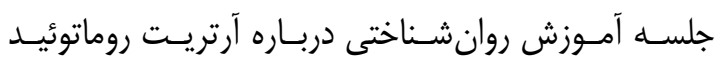

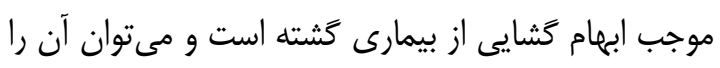

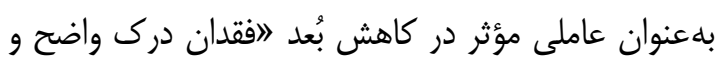

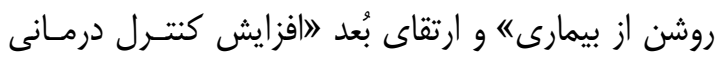

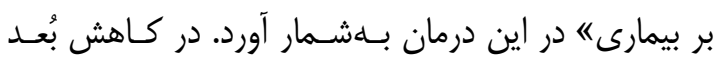


مطلـوب دركيـر شــده و احسـاس تسـلط بــر شــرايط و خودكارآمدى در آنها افزايش مركى ندابد.

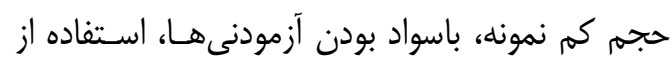

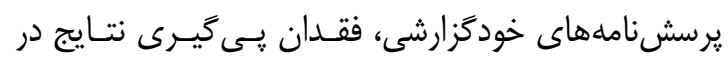

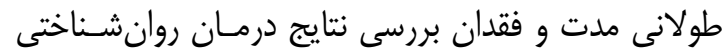

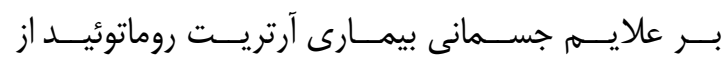

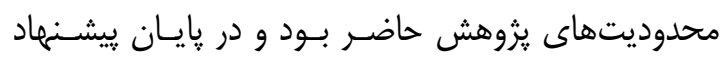

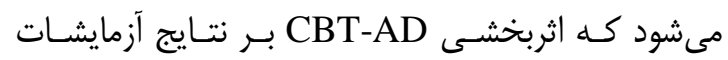
بالينى و فعاليت بيمارى RA در نمونهاى وسيعتر بهكسار

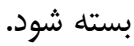
در مجموع، درمان CBT-AD قادر است با تكيسه بــر

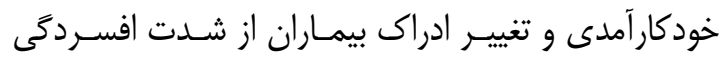
كاسته و با تصحيح تحريفات شناختى و بازنشانى تفكـرات انطباقى بازنمايىهاى ادراكى فرد را بييرامون بيمارى تغيير

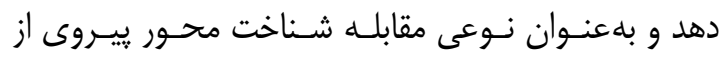

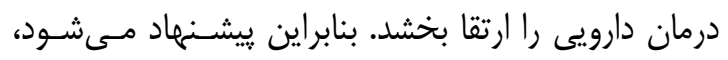

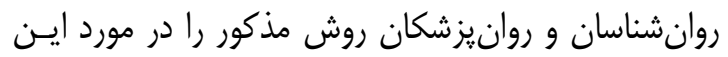

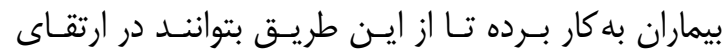

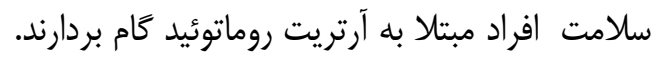

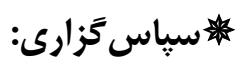

همكارى شركت كنندكان در اين يثوهش شرط اصـلى

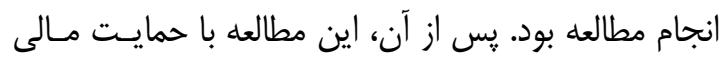
دانشگاه آزاد اسلامى واحد البرز انجام شد.

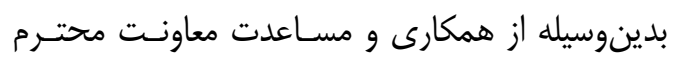

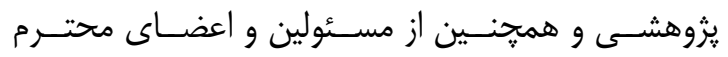

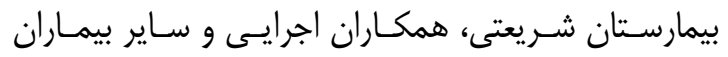
شركت كننده در يزوهش، تقدير و قدردانى مى گــردد. ايـن

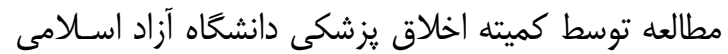

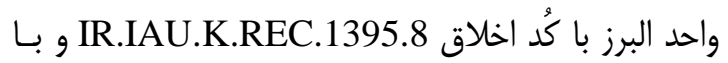
كد IRCT20141012019511N3 در مركـز كارآزمـايى اليق

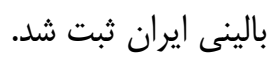

در نهايت، بـراى مقابلـه بــا عـوارض جـانبى داروهـا،

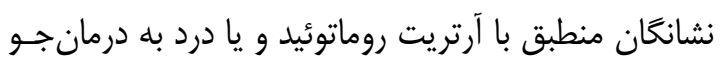

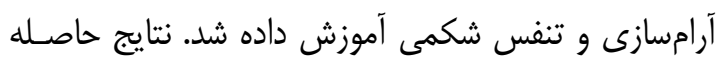

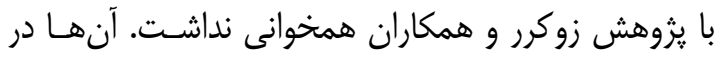
يزوهش خود با هدف قرار دادن ادراك و باورهاى بيمـاران

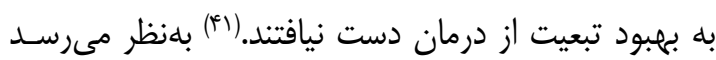

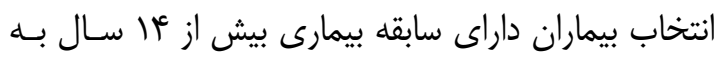

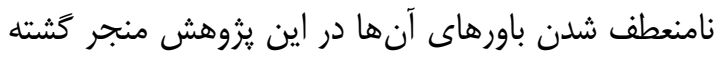

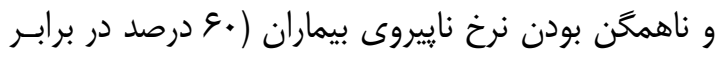

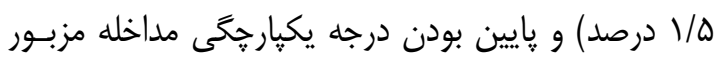

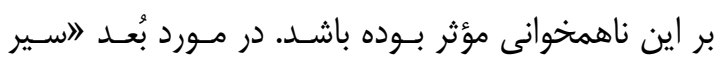

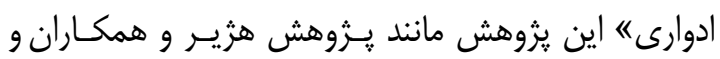

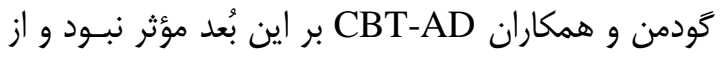

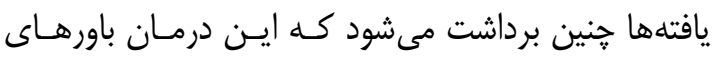

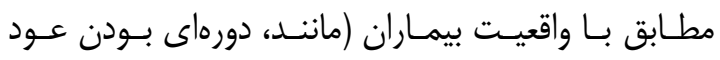

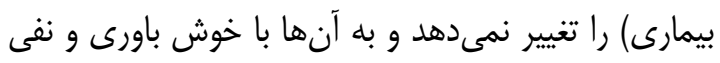

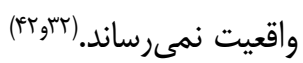
مزيت مطالعه حاضر در واكاوى اثربخشى CBT-AD

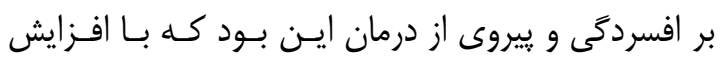

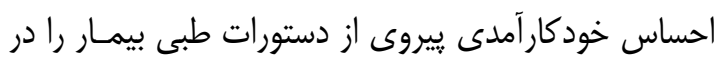

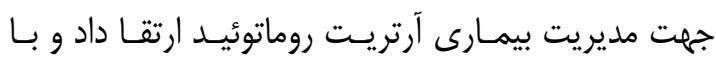

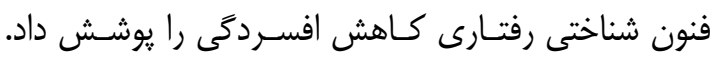

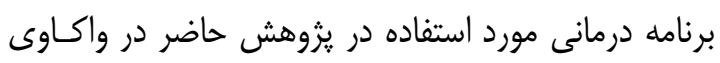

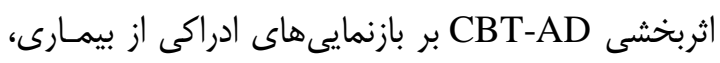

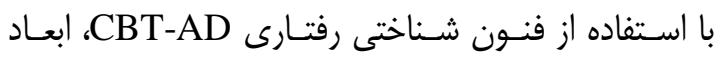

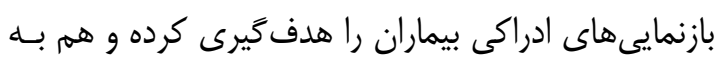

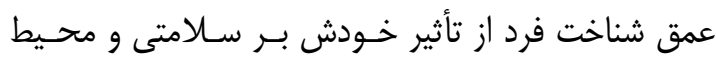

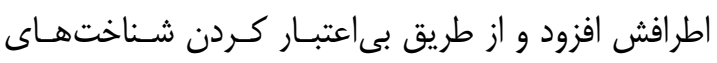

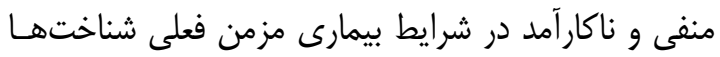
و ادراك منفى را تعديل نمود. منطق نهفته در CBT-AD از اين ايده برخاسته است

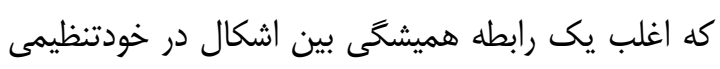

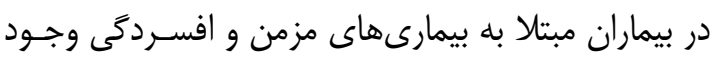

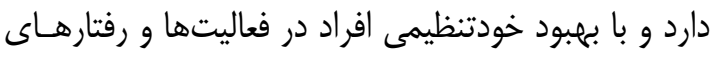


1. Cross M, Smith E, Hoy D, Carmona L, Wolfe F, Vos T, et al. The global burden of rheumatoid arthritis: estimates from the global burden of disease 2010 study. Ann Rheum Dis 2014; 73(7): 1316-22. doi: 10. 1136/annrheumdis-2013-204627.

2. Askary-Ashtiani AR, Mousavi SJ, Montazeri A, Shamsollahi S, Parnianpour M. Cultural adaptation and validation of the Persian version of the arthritis impact measurement scales 2-short form in patients with osteoarthritis of the knee. Disabil Rehabil 2009; 31(25): 2081-7. doi: 10.3109/ 09638280902918746.

3. Blum MA, Koo D, Doshi JA. Measurement and rates of persistence with and adherence to biologics for rheumatoid arthritis: a systematic review. Clin Ther 2011; 33(7): 901-13. doi: 10.1016/j.clinthera.2011.06.001. 4. Brus H, van de Laar M, Taal E, Rasker J, Wiegman O. Determinants of compliance with medication in patients with rheumatoid arthritis: the importance of self-efficacy expectations. Patient Educ Couns 1999; 36(1): 57-64. doi: 10.1016/S0738-3991(98) 00087-1.

5. Doyle DV, Perrett D, Foster OJ, Ensor M, Scott DL. The long-term use of Dpenicillamine for treating rheumatoid arthritis: is continuous therapy necessary? $\mathrm{Br}$ J Rheumatol 1993; 32(7): 614-7.

6. Koncz T, Pentek M, Brodszky V, Ersek K, Orlewska E, Gulacsi L. Adherence to biologic DMARD therapies in rheumatoid arthritis. Expert Opin Biol Ther 2010; 10(9): 1367-78. doi: 10.1517/14712598.2010.510508.

7. Pullar T, Peaker S, Martin MF, Bird HA, Feely MP. The use of a pharmacological indicator to investigate compliance in patients

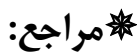

with a poor response to antirheumatic therapy. Br J Rheumatol 1988; 27(5): 381-4.

8. Contreras-Yáñez I, Ponce De León S, Cabiedes J, Rull-Gabayet M, Pascual-Ramos $\mathrm{V}$. Inadequate therapy behavior is associated to disease flares in patients with rheumatoid arthritis who have achieved remission with disease-modifying antirheumatic drugs. Am J Med Sci 2010; 340(4): 282-90. doi: 10.1097/ MAJ.0b013e3181e8bcb0.

9. Van den Bemt BJf. Optimizing pharmacotherapy in patients with rheumatoid arthritis: an individualized approach: [S1: sn]; 2009.68-83.

10. Viller F, Guillemin F, Briancon S, Moum $\mathrm{T}$, Suurmeijer T, van den Heuvel W. Compliance to drug treatment of patients with rheumatoid arthritis: a 3 year longitudinal study. J Rheumatol 1999; 26(10): 2114-22.

11. Englbrecht $M$, Alten $R$, Aringer $M$, Baerwald C, Burkhardt H, Eby $\mathrm{N}$, et al. FRI0142 High prevalence of depression in patients with rheumatoid arthritis-Data from the large cross-sectional Vadera II study. Ann Rheum Dis 2016; 75(Suppl 2): 2-80. doi: 10. 1136/annrheumdis-2016-eular.3236.

12. Margaretten M, Julian L, Katz P, Yelin E. Depression in patients with rheumatoid arthritis: description, causes and mechanisms. Int J Clin Rheumatol 2011; 6(6): 617-23. doi: 10. 2217/IJR.11.6

13. Brandstetter S, Riedelbeck G, Steinmann M, Loss J, Ehrenstein B, Apfelbacher C. Depression moderates the associations between beliefs about medicines and medication adherence in patients with rheumatoid arthritis: cross-sectional study. J Health Psychol 2016: 1359105316646440. doi: 10.1177/1359105316646440. 
14. Katon W, Ciechanowski P. Impact of major depression on chronic medical illness. $\mathrm{J}$ Psychosom Res 2002; 53(4): 859-63. doi: 10. 1016/S0022-3999(02)00313-6.

15. Rathbun AM, Reed GW, Harrold LR. The temporal relationship between depression and rheumatoid arthritis disease activity, treatment persistence and response: a systematic review. Rheumatology (Oxford) 2013; 52(10): 1785-94. doi: 10.1093/ rheumatology/kes356.

16. Joyce AT, Smith P, Khandker R, Melin JM, Singh A. Hidden cost of rheumatoid arthritis (RA): estimating cost of comorbid cardiovascular disease and depression among patients with RA. J Rheumatol 2009; 36(4): 743-52. doi: 10.3899/jrheum.080670.

17. Gonzalez JS, Penedo FJ, Llabre MM, Durán RE, Antoni MH, Schneiderman N, et al. Physical symptoms, beliefs about medications, negative mood, and long-term HIV medication adherence. Ann Behav Med 2007; 34(1): 46-55. doi: 10.1080/ 08836610701495565

18. Covic T, Tyson G, Spencer D, Howe G. Depression in rheumatoid arthritis patients: demographic, clinical, and psychological predictors. J Psychosom Res 2006; 60(5): 469-76. doi: 10.1016/j.jpsychores.2005.09. 011.

19. Reach G. The mental mechanisms of patient adherence to long-term therapies. mind and care. $2^{\text {nd }}$ ed. New York: Springer Press; 2015; 128-37.

20. Hale ED, Treharne GJ, Kitas GD. The Common-Sense Model of self-regulation of health and illness: how can we use it to understand and respond to our patients' needs? Rheumatology (Oxford) 2007; 46(6): 904-6. doi: 10.1093/rheumatology/kem060.

21. Safren S, Gonzalez J, Soroudi N. Coping with chronic illness. A cognitive-behavioral therapy approach for adherence and depression. 1st ed. New York: Oxford University Press; 2007; 87-90.

22. Safren SA, Hendriksen ES, Mayer KH, Mimiaga MJ, Pickard R, Otto MW. Cognitive-behavioral therapy for HIV medication adherence and depression. Cogn Behav Pract 2004; 11(4): 415-24.

23. Haghighi TH, Dousty Y, Mirzaian B, Kazem FM. Effectiveness of group cognitivebehavioral therapy on illness perception, pain perception and life quality in patients with rheumatoid arthritis. Scientific J Kurdistan Univ Med Sci 2015;20(3): 45-57 [In Persian]. 24. Leventhal H, Leventhal EA, Contrada RJ. Self-regulation, health, and behavior: a perceptual-cognitive approach. Psychol Health 1998; 13(4): 717-33. doi: 10.1080/ 08870449808407425.

25. Groarke A, Curtis R, Coughlan R, Gsel A. The impact of illness representations and disease activity on adjustment in women with rheumatoid arthritis: a longitudinal study. Psychol Health 2005; 20(5): 597-613. doi: 10. 1080/14768320500094177.

26. Ferguson A, Ibrahim FA, Thomas V, Weinman J, Simpson C, Cope AP, et al. Improving medication adherence in rheumatoid arthritis (RA): a pilot study. Psychol Health Med 2015; 20(7): 781-9. doi: 10.1080/13548506.2015.1009917.

27. World Medical Association. World Medical Association Declaration of Helsinki: ethical principles for medical research involving human subjects. JAMA 2013; 310(20): 2191-4. doi: 10.1001/jama.2013. 281053.

28. Kay J, Upchurch KS. ACR/EULAR 2010 rheumatoid arthritis classification criteria. Rheumatology 2012; 51(suppl_6): vi5-9. 
doi: 10.1093/rheumatology.2012.kes279.

29. Little RJ, D'agostino R, Cohen ML, Dickersin K, Emerson SS, Farrar JT, et al. The prevention and treatment of missing data in clinical trials. $\mathrm{N}$ Engl J Med 2012; 367(14): 1355-60. doi: 10.1056/ NEJMsr 1203730.

30. Moss-Morris R, Weinman J, Petrie K, Horne R, Cameron LD, Buick D. The revised illness perception questionnaire (IPQ-R). Psychol Health 2002; 17(1): 1-16. doi: 10. 1080/08870440290001494.

31. Ghasemzadeh H, Arjmand M, Mohsenifar $\mathrm{S}$, Hamidpour H. The revised illness perception questionnaire. Available from: https://www.uib.no/ipq/index.html (accessed 10 Oct 2007).

32. Hazhir F, Ahadi H, Pourshahbaz A, Rezaei M. The effectiveness of cognitivebehavior therapy on illness representations of multiple-sclerosis and improving their emotional states. J Kermanshah Univ Med Sci 2012; 15(6): 415-26. [In Persian]

33. Rajabi G, Karjo KS. Psychometric properties of a persian-language version of the Beck depression inventory-second edition (BDI-II-persian). Training Measurement 2013; 3(10): 139-57. [In Persian]

34. Arjmandnia A, Namjoo S. Efficacy of memory specificity training (MEST) on underlying mechanisms of over general autobiographical memory (OGM) in people with major depression and childhood traumatic experience. J Isfahan Med Sch 2015; 33(329): 442-56. [In Persian]

35. Hays RD. The Medical Outcomes Study (MOS) measures of patient adherence. 2nd ed. Oxford: Blackwell Science; 1994. 505-17.

36. Zarani F, Besharat MA, Sarami G, Sadeghian S. An information-motivationbehavioral skills (IMB) model-based intervention for CABG patients. Int J Behav Med 2012; 19(4): 543-9. doi: 10.1177/ 1359105309357092.

37. Fransen J, Stucki G, van Riel PL. Rheumatoid arthritis measures: Disease Activity Score (DAS), Disease Activity Score-28 (DAS28), Rapid Assessment of Disease Activity in Rheumatology (RADAR), and Rheumatoid Arthritis Disease Activity Index (RADAI). Arthritis Care Res 2003; 49(S5): S214-24. doi: 10.1002/art.11407

38. Morowatisharifabad $M$, Nadrian $H$, Soleimani Salehabadi H, Mazloomy Mahmoodabad S, Asgarshahi M. The relationship between predisposing factors and self-care behaviors among patients with rheumatoid arthritis. Hayat 2009; 15(3): 3951. [In Persian]

39. Nazemi Ardakani F, Bahrami H, Alipor A, Bayat N. Effectiveness of religious spiritual intervention based on Islamic approach on psychological and immune indices in patients with Rheumatoid Arthritis. J Psychol Res Quarterly 2016; 6(4): 113-31. [In Persian]

40. Nazemi Ardakani F, Bahrami H. Effectiveness of cognitive behavioral stress management intervention on psychological and immune factors in patients with Rheumatoid Arthritis referred to the rheumatology clinics of Baghiat Allah hospital. J Military Psychology 2015; 6(22): 55-6. [In Persian]

41. Zwikker $\mathrm{HE}$, van den Ende $\mathrm{CH}$, van Lankveld WG, den Broeder AA, van den Hoogen FH, van de Mosselaar B, et al. Effectiveness of a group-based intervention to change medication beliefs and improve medication adherence in patients with rheumatoid arthritis: a randomized controlled trial. Patient Educ Couns 2014; 94(3): 356- 
61. doi: 10.1016/j.pec.2013.12.002.

42. Goodman D, Morrissey S, Graham D, Bossingham D. The application of cognitivebehaviour therapy in altering illness representations of systemic lupus erythematosus. Behav Change 2005; 22(3): 156-71. doi: 10.1375/bech.2005.22.3. 156. 